\title{
Modelling Bedrock Topography
}

\author{
Nils-Otto Kitterød ${ }^{1,2}$ and Étienne Leblois ${ }^{2}$ \\ ${ }^{1}$ Norwegian University of Life Sciences, Environmental Sciences and Natural Resource Management, P.Box 5003, N-1432 \\ Ås, Norway. \\ 2 Irstea, UR HHLY, Centre de Lyon-Villeurbanne, 5 rue de la Doua BP 32108, F-69626 Villeurbanne Cedex, France.
}

Correspondence: Nils-Otto Kitterød (nils-otto.kitterod@nmbu.no)

\begin{abstract}
The access to digital information from remote sensing; geological mapping; and public databases give an opportunity to express the surface of the bedrock as a mathematical estimation problem. We modelled the bedrock topography as a stochastic function in space. The function is given with high precision in areas where the bedrock is exposed to the surface, but unknown in areas covered by sediments except for a limited number of point information (viz boreholes; wells; geotechnical surveys). Two different approaches were evaluated to reveal the local trend of the bedrock surface: Firstly, we applied the statistical relation between the horizontal distance $(L)$ to the nearest bedrock outcrop and the observed sediment depth $(D)$ in boreholes. The relation between $D$ and $L$ was applied in ordinary kriging and cokriging to include the local trend in the estimation. Secondly, we applied inverse modelling of the Poisson's equation to model the local trend. After minimizing the difference between the point observations and the parabolic surface from the Poisson's equation, we did ordinary kriging of the residuals between the optimal parabolic function and the observations. These approaches were tested against observations from a test site. Estimates derived from the Poisson's equation gave a lowest mean absolute error for cross-validation by leaving one observation out. Ordinary kriging gave a least mean absolute error when an independent dataset was used for cross-validation. The results show that the extreme large soil depths were better reproduced if the local trend was included in the estimation procedure.
\end{abstract}

\section{Introduction}

The bedrock topography plays a cardinal role in many different contexts. One example is the urban environment where important infrastructure is located in the subsurface. Another example is the mining of resources from the bedrock. Extraction of water or energy from boreholes may serve as an illustration. Boreholes drilled in locations with unconsolidated sediments need casings to prevent sediments from entering into the boreholes. If the sediment thickness is substantial, the drilling costs may be larger than the benefits of the borehole. Therefore, prior to drilling a borehole, estimates of the bedrock topography may act as a guideline to avoid unprofitable investments. In this context, the uncertainties of the estimates are as important as the most likely altitude of the bedrock topography. The research challenge is to capitalize on the available information to minimize the estimation uncertainties.

In the case study presented below, point observations of unconsolidated sediment thickness are taken from the Norwegian well database GranADA (NGU, 2017a). The database was established as a result of national legislation (Lovdata, 1996), and 
the Geological Survey of Norway (www.ngu.no) made the data publicly available. Such databases represent a great value to the society, in particular, if the information can be generalized and transferred to locations with no direct measurements.

Even though the results of this study are relevant for urban planning, the motivation for the study was a basic question in hydrology: What is the relation between the shallow groundwater in the sediments and the bedrock? Due to an increasing population and global warming, society needs more precise guidelines on problems related to sustainable management of water resources. There is a great challenge to identify catchment characteristics that explain how precipitation and snowmelt events transform to runoff in streams and rivers. A common denominator for many of these challenges is the residence time of water in the catchment. A part of the problem is to identify the focusing effects of water flow at different scales. Focusing of flow means that water is channelled by funnelling effects to a minor part of the flow domain. At the interface between saturated and unsaturated water flow the non-linear increase in hydraulic conductivity may give rise to fast transport of water. Graham et al. (2010) and Graham and McDonnell (2010) used field experiments and modelling results to demonstrate the importance of threshold effects in runoff to rainfall events. Above a given threshold the runoff increased dramatically with the rainfall. In such cases a major fraction of the subsurface flow took place at the interface between the sediments and the less permeable bedrock. Hopp and McDonnell (2009) used a synthetic dataset to show the importance of surface topography, soil depth and bedrock topography to simulate rainfall runoff response. They concluded that the subsurface connectivity of saturated areas explained the runoff characteristics. Gabrielli et al. (2012) studied the relation between runoff and groundwater in sediments and bedrock in hillslope catchments in New Zealand and Oregon, US. In both hillslopes, the bedrock influenced the stream flow, but rapid subsurface stormflow was apparently most important if the bedrock had low permeability compared to the soil. Based on a large dataset Tromp-van Meerveld and McDonnell (2006a) showed that pipe flow, matrix flow and total flow had a threshold response to precipitation. Total flow increased two orders of magnitude if precipitation increased a specified threshold. From their analysis, they concluded that bedrock topography governed the upstream contributing area, not the surface area as usually assumed. In a following study Tromp-van Meerveld and McDonnell (2006b) showed that micro depressions in the bedrock surface was filled before they contributed to subsurface runoff. Freer et al. (2002) studied the relation between the hydrological response of a storm event and the bedrock topography in the Panola Mountain Research Watershed in Georgia, USA. They concluded that in cases where the bedrock had low permeability, the bedrock topography was important for the groundwater level, which in turn explained the large scale hydraulic connectivity of the subsurface. Connectivities of macrostructures are important for estimation of peak flow and recession of water in the catchment. Several other studies also elucidate the importance of the bedrock topography to understand hydrological and geochemical response (Genereux et al., 1993a, b; Mulholland, 1993; Hinton et al., 1993; Jencso et al., 2009).

55 The purpose of the current project was to explore different approaches for mathematical modelling of the bedrock topography. The estimation uncertainty was modelled by standard methods in Gaussian statistics as ordinary kriging and cokriging (Journel and Huijbregts, 1989; Isaaks and Srivastava, 1989; Deutsch and Journel, 1998). Because the bedrock topography is not a stationary stochastic function in space, it was necessary to apply trend analysis to minimize the estimation variance. Two different hypotheses were evaluated (Fig.1): Firstly, we postulate a linear relation between the sediment thickness $D(u)$ and 
the horizontal distance to nearest bedrock outcrop $L(u)$, where $u$ is the geographical location. Secondly, we applied inverse modelling of the Poisson's equation to adapt a parabolic function to the bedrock topography.

Using $L(u)$ in the estimation procedure was inspired by an intuitive procedure among drill operators: Based on previous experiences from a given area, it is often possible to judge the sediment thickness $D(u)$ at a location $u$, by simple visual inspection of the horizontal distance $L$, to the nearest bedrock outcrop. The statistical relation between $D(u)$ and $L(u)$ was used in cokriging and ordinary kriging to evaluate the effect on the estimation variance.

The Poisson's equation offers some interesting properties in this context (Kazhdan et al., 2006; Calakli and Taubin , 2011; Liu, 2018). Firstly, the Poisson's equation yields parabolic functions in space, which have similarities to the famous U-shaped valleys that are typical for areas excavated by glaciers. Secondly, the Poisson's equation is sensitive to the boundary conditions. If the altitude is known, we can capitalize on this sensitivity by using this information in areas where the bedrock is exposed to the atmosphere. Today, Digital Elevation Models (DEM) with high resolution are available for large parts of the world. Thirdly, in areas covered by sediments, inverse modelling of the Poisson's equation can be used to fit a parabolic surface to the point observations of the sediment thickness. After inverse modelling of the Poisson's equation, we applied ordinary kriging on the residuals, i.e. the difference between observed sediment thickness and the optimal parabolic function.

Kazhdan et al. (2006) applied numerical solutions of the Poisson's equation as a filtering method for surface reconstruction.

75 Conventional application of the Poisson's equation apparently requires that the reconstruction domain is minor compared to the surface that is exposed to observations. The opposite is true in this case study: The unknown domain is large compared to the exposed bedrock. To overcome this problem, we used point information from boreholes for inverse modelling of a constant parameter in the Poisson's equation. From this procedure, we minimized the differences between the parabolic surface and the empirical point observations.

In this project we had access to spatial information of the surface altitude terrain $T(u)$ [m a.m.s.l.], given as digital elevation models (DEM). From Digital Quaternary maps (DQM), we derived a rock indicator function $R(u)$, that identifies where the bedrock was exposed to the atmosphere, $R(u)=1$, or buried under different kind of deposits, $R(u)=0$. In addition to $T(u)$ and $R(u)$, we also had access to a limited number of point information $u_{i}$ of the sediment depth $D\left(u_{i}\right)$. Thus, the bedrock topography is given by:

where $D(u)=0$ if $R(u)=1$, and $D(u)>0$ if $R(u)=0$. The target of the study was to minimize the estimation uncertainty $\epsilon(u)$.

The uncertainties depend on the estimation method and the empirical data. For every location of interest $u$, the geostatistical methods provide the conditional cumulative probability density functions (cdf) of the bedrock topography $B$, and the sediment thickness $D$. The cdf of $B(u)$ or $D(u)$ in location $u$ is denoted $F(u)$. The uncertainties were quantified in terms of percentiles $\xi_{p}$, where $p \in[0,1]$. In the case study presented below, we let $p=[0.05,0.1,0.25,0.5,0.75,0.9,0.95]$.

As indicated above, we used borehole information from mainland Norway $(\Omega)$ stored in the GRANADA database (NGU, 2017a) as empirical input to the modelling. The global data was used to estimate covariance- and cross-covariance functions. 
Local boreholes were used for conditional estimation and inverse modelling of the constant parameter in the Poisson's equation.

The modelling procedures were evaluated with data from a local study area Øvre Eiker located $60 \mathrm{~km}$ west of Oslo (Fig.2).

In a previous study Kitterød (2017) discussed the challenges of utilizing the GRANADA database for estimation of sediment thickness. The main problems were related to small-scale variance; preferential sampling; and bias in the empirical data material. The small-scale variance was about half of the total variance. This explains why less than 50\% accuracy can be expected. Preferential sampling refers to the clustering of data in some areas, while other areas have a sparse density of measurements. The GRANADA database had a high density of recordings in urban areas, but few observations in sparsely populated regions. To derive statistical moments and variograms from such data, it is necessary to perform some sort of declustering, which means that areas with high sampling density receive less weight than areas with sparse sampling (Omre, 1984). For the present study, the semivariograms- and cross-semivariogram functions were based on declustered data calculated according to the grid algorithm suggested by Deutsch and Journel (1998). Bias is a general challenge in geosciences, and a number of studies discuss how to control or suppress systematic mismatch between measurements or simulation results on one hand, and the reality on the other (Terink et al., 2010; ?). One option is to apply trend analysis and perform the geostatistical analysis on the residuals (Pyrcz and Deutsch, 2003). This approach assumes that it is possible to identify the trend, and secondly, that there are no cross-correlation between the trend(s) and the residuals. If the physical reason for the bias is known, it might be possible to assess observations or simulations of the governing physics and apply these data as a secondary variable to control bias (Wolff et al., 2015). In this sense, the trend analysis we propose can be viewed as a method for suppression of bias. To test the two procedures, two different types of cross-validation was performed: First, cross-validation was undertaken on boreholes sampled before 2010. This was done by leaving one observation out. The second cross-validation was done on boreholes and sedimentary wells recorded after 2010. Because the second cross-validation was done on independent data not included in the parameter inference, this procedure was called jackknife cross-validation.

The results were evaluated according to: The mean absolute error $M_{A E}$; accuracy $A_{C}$, and precision $P_{C}$ (Goovaerts et al., 2005). For the kriging methods we also calculated the percentile score for the observations at the locations of the crossvalidation wells and boreholes.

Before presenting the results, we describe the empirical data and show how this material can be used to derive the spatial functions we needed for the geostatistical modelling. The methods we employed are documented in the literature, but to make the results easier to reproduce for interested readers, the main equations were recapitulated and explained in the method section below. Finally, the results were related to the problem of bias and interpreted in the light of the local geology.

\section{Data material}

As indicated above, we employed three sources of information for the current study: (i) Point observations of sediment thickness, $D\left(u_{i}\right)$; (ii) Digital Quaternary maps, DQM; and (iii) Digital elevation model of the surface, DEM. In addition, we also had access to geological maps of the bedrock for the study area. Since the modelling target was the bedrock topography, it is pertinent to include a brief description of the most prominent geological structures in the area. 


\subsection{Local geology}

The study area $\emptyset$ vre Eiker $(9 \mathrm{~km} \times 7.2 \mathrm{~km})$, is located about $60 \mathrm{~km}$ west of Oslo (Fig.2). Øvre Eiker is a part of Vestfold graben, which is one of the three main graben structures in the Oslo Rift. Large parts of the Vestfold graben come from batholithic intrusions and consists mainly of biotite granite. At the highest altitudes in the eastern parts of the study area, the bedrocks belong to the Glitrevann caldera, which was formed as part of the plutonic intrusion in Permian time (299 - 252 mill. years BP). At the eastern side of the valley, the bedrocks are mainly shales, marble and limestones from Ordovicium (488 - 440 mill. years BP). The bedrocks at the western side of the valley are mainly quartzites (estimated deposition age about 1475 mill. years BP) and different kinds of gneiss (estimated intrusion age of about 1500 mill. years BP). At large, the topography of the study area mirrors the character of the bedrock, with hard resistant bedrock at high altitudes and softer bedrocks in the valleys. More information on the bedrock geology can be found in Andersen et al. (2008) and at NGU (2017b).

\subsection{Quaternary maps and surface elevation}

Digital Quaternary maps, DQM (NGU, 2017c), was used to identify locations where the bedrock was exposed to the atmosphere or covered with a thin and patchy layer of organic matter $R(u)=1$ (37\% of the study area). For simplicity, the area where $R(u)=1$ is referred to as exposed bedrock in this article. The remaining area, where $R(u)=0(63 \%)$, was covered by unconsolidated material (Fig.3). The most frequent sediment in the area was marine deposits, which cover about $27 \%$ of the area. The marine limit of the study area was leveled to $194 \mathrm{~m}$ above present mean sea level (Bargel, 1987). More than 70\% of the surface area covered by sediments $(R(u)=0)$, was below the marine limit, while more than $75 \%$ of the exposed bedrock $(R(u)=1)$, was located above this altitude (Fig.3).

Till deposits were the second most frequent surface sediment, which were exposed in about $13 \%$ of the study area. Most of the tills were deposited as a relatively thin layer above the bedrock, and more than $95 \%$ of the exposed tills were located above the marine limit. For simplicity, we also included front moraine in the till category for the present study, which implies that the sediment thickness may be larger in some locations. Glaciofluvial sediments were deposited below $200 \mathrm{~m}$ a.m.s.l. and fluvial sediments below $120 \mathrm{~m}$ a.m.s.l. (Fig.3). About 8\% of the study area was covered by avalanches or weathered material. Peat and swamps covered less than $2 \%$ of the area, which were most frequent at high altitudes. A minor fraction of the area $(0.14 \%)$ was anthropogenic material.

\subsection{Sediment thickness and horizontal distance to bedrock outcrop}

Point observations of sediment thickness $D\left(u_{i}\right)$ for mainland Norway was taken from the public well data base GRANADA (NGU, 2017a). We used DQM to calculate horizontal distance to the nearest bedrock outcrop $L\left(u_{i}\right)$ for GRANADA boreholes (Kitterød, 2017). This dataset was used to derive global statistical parameters for spatial variance and covariance for $D\left(u_{i}\right)$ and $L\left(u_{i}\right), i=1, \ldots, N$, where $N=19682$ for the global dataset. GRANADA boreholes located within the Øvre Eiker study area recorded prior to 2010 were used for a primary cross-validation by leaving one borehole out. All of these wells - marked with 
red dots in Fig.2, were later used to calculate $F(u \mid \mathcal{A})$, where $\mathcal{A}$ denotes all available information recorded before 2010. These results were compared to the sedimentary wells and boreholes recorded after 2010 as a jackknife cross-validation.

In addition to point observations of $D\left(u_{i}\right)$, we used $R(u)$ to calculate $L(u)$ in a regular grid with spatial resolution of $\Delta x \times \Delta y=25 \mathrm{~m} \times 25 \mathrm{~m}$. The purpose was to evaluate whether or not modelling results were improved if local information of $L(u)$ was included as a secondary function.

\section{Geostatistical modelling}

The methods we applied for this study were based on multi-Gaussian statistics. Gaussian theory is documented in textbooks (Isaaks and Srivastava, 1989; Journel and Huijbregts, 1989; Deutsch and Journel, 1998), and will not be reproduced here, except for details that are relevant for the present study. Before the modelling took place, the GRANADA data required pre-processing. This was necessary because the GRANADA wells were clustered and the probability density functions (pdfs) of the variables were not Gaussian distributed.

\subsection{Declustering}

Boreholes and wells are usually located in populated areas, which means that many of the GRANADA recordings are from urban areas, and few recordings from rural areas. When such data is used to calculate average properties, uneven sampling will affect the statistics because oversampled domains will dominate. To suppress such cluster effects, each observation received a weight calculated as a function of the distance to other boreholes. Boreholes located close to each other was given less weight than boreholes located far from each other. Calculation of declustering weights were done according to the moving grid algorithm suggested by Deutsch (1989), and results presented in Kitterød (2017). It should be noted that declustering weights do not change the value of the observations that we used for conditional modelling. The weights are only applied on the observations for calculation of experimental semivariograms and statistical moments.

\subsection{Gaussian transformation}

We applied two methods to approach Gaussian distributions of the involved variables. For ordinary kriging $(O K)$ and cokriging $(C K)$, we utilized the normal score transform (Deutsch and Journel, 1998), while bedrock kriging $(B K)$ was done on logarithmic values. For the sake of completeness, $O K$ was also performed on logarithmic values. After calculations, the results were back-transformed to the engineering values (metric units) for cross-validation, either by the inverse normal score transform or the inverse log-normal cdf.

The normal score transform is based on the empirical data material. First, the observations $Y\left(u_{i}\right)$, were sorted and ranked from minimum to maximum, $i=1, \ldots, N$, where $N$ is the number of observations. Then, a standard normal variable $Z_{i} \in$ $G(0,1), i=1, \ldots, N$, were sorted and ranked from minimum to maximum value. The rank $k$ of $Z$ is the normal score transform of $Y_{k}(u)$ (Deutsch and Journel, 1998; Goovaerts et al., 2005):

$Z_{k}(u)=\phi\left(Y_{k}(u)\right)$, 
where $\phi$ denote the normal score transform of rank $k$, and the observations $Y_{k}(u)$ are either sediment depth $D(u)$, or horizontal distance to nearest bedrock outcrop $L(u)$. Thus, the normal score transform of $D(u)$ and $L(u)$ was done independent of each other.

For the lognormal transform, $Z\left(u_{i}\right)=\ln \left(Y\left(u_{i}\right)\right)$, where $Y\left(u_{i}\right)[\mathrm{m}]$ is the observed values, the percentiles $Y_{\xi}(u)$, was derived by the same token as for the normal score transform:

$Y(u ; \xi)=\varphi^{-1}\left(F_{Z}(u ; \xi) \mid \hat{Z}(u), \sigma_{Z}^{2}(u)\right)$

where $\varphi^{-1}$ is the inverse of the lognormal $\operatorname{cdf} F_{Z}(u)$, which was given from the kriging estimates $\hat{Z}(u)$ and the estimation variance $\sigma_{Z}^{2}(u)$.

\subsection{Semivariograms and cross-semivariogram}

The normal score semivariograms $\left[\gamma_{D}, \gamma_{L}\right]$ and cross-semivariogram $\left[\gamma_{D L}\right]$ functions used in the current case study were taken from Kitterød (2017), and are therefore not reproduced here. Logarithmic semivariograms $\left(Z(u)=\ln [D(u)]\right.$ and $\kappa\left(u_{i}\right)=$ $\ln \left[D\left(u_{i}\right) / L\left(u_{i}\right)\right]$ ) were used for the bedrock kriging $(B K)$ method (c.f. section 3.5 below). All variograms used for the present study were calculated with observations from the global GRANADA database. The covariance functions $C(h)$, were used to solve the kriging equations, which means that the semivariograms were subtracted from the total variance (the nugget $C_{0}$ and the sill $C_{1}$ ):

$C(h)=C_{0}+C_{1}-\gamma(h)$,

where $h$ is the separation distance and $\gamma(h)$ is the semivariogram function:

$\gamma(h)=C_{0}+C_{1}\left(1-\exp \left(-\beta(h / a)^{\alpha}\right)\right.$,

where $a$ is the correlation length (or range in geostatistical terms), the practical range $\beta$ denotes the variance at the chosen distance $h=a$. Here, we let $\beta=\ln (20)$, which means that $C(a)=0.95\left(C_{0}+C_{1}\right)$. The exponential parameter $\alpha, 1 \leq \alpha \leq 2$, determines the noisiness of $Z(u)$. Maximum noisiness is obtained if $\alpha=1$, and minimum if $\alpha=2$.

\subsection{Ordinary kriging and cokriging}

Estimates of expected value $\hat{Z}(u)$ and variance $\sigma^{2}(u)$ were obtained by solving the classical ordinary kriging $(O K)$ and the cokriging $(C K)$ equations. Written in terms of matrix notations the expected value of the Gaussian transformed variable $Z \in N(\hat{Z}, \sigma)$ is written:

$\hat{Z}=\mathbf{Z}_{o b s} \boldsymbol{\Lambda}$,

215 where $\mathbf{Z}_{o b s}$ is a vector of normal transformed observations $\left(\mathbf{Z}_{o b s} \in N\right)$, and $\boldsymbol{\Lambda}$ is the kriging weights, which are found by solving:

$\mathbf{X}=\mathbf{C}^{-1} \mathbf{C}_{\mathbf{u}}$, 
where $\mathbf{C}^{-1}$ denotes the inverse of the covariance matrix $\mathbf{C}$, and the estimation variance $\sigma^{2}$ is written:

$\sigma^{2}(u)=\operatorname{Var}[Z]-\mathbf{X}^{T} \mathbf{C}_{\mathbf{u}}$,

where the total variance: $\operatorname{Var}[Z]=\operatorname{Var}\left[Z_{D}\right]$ for ordinary kriging, and $\operatorname{Var}[Z]=\operatorname{Var}\left[Z_{D} Z_{L}\right]$ for cokriging, and $\mathbf{X}^{T}$ is the transposed of the matrix $\mathbf{X}$, where the Lagrange multipliers are included in addition to the covariance matrix (Eqs. 17 to 23 in Kitterød (2017)). For more details on the matrix notation of kriging and cokriging c.f. Myers (1982).

\subsection{Bedrock kriging}

Several methods exist for including secondary information in the estimation procedure (Deutsch and Journel, 1998; Goovaerts et al., 2005). Here, we suggest a method, labelled bedrock kriging $(B K)$, which is less formal than cokriging or kriging on residuals, however, it incorporates the local relation between sediment thickness $D$ and the horizontal distance to bedrock outcrop $L$. This was done by ordinary kriging of point information of $Z\left(u_{i}\right)=\ln \left(D\left(u_{i}\right)\right)$ and $\kappa\left(u_{i}\right)=\ln \left[D\left(u_{i}\right) / L\left(u_{i}\right)\right]$ and back transformed by the lognormal pdf to get the percentiles $\xi$. The back transformed $\kappa(u)$ estimates were then multiplied by the gridded horizontal distance to the bedrock $L(u)$, which gave an estimate of $D(u)$ that included the spatial information of $L(u)$. By weighting the two estimates of $D(u)$ in such a way that close to the the boreholes where we had point information of $D\left(u_{i}\right)$ (i.e. in ), the ordinary kriging results of $Z\left(u_{i}\right)=\ln \left(D\left(u_{i}\right)\right)$ received highest weights, while in distant areas from the (borehole) point observations the $\kappa(u)$ estimates received most weight. In this study, the weights $\omega(u)$ were derived from the square root of the estimation variance $\sigma^{2}(u)$ :

$\omega(u)=\frac{\sigma_{Z}(u)-\min \left(\sigma_{Z}\right)}{\max \left(\sigma_{Z}\right)-\min \left(\sigma_{Z}\right)}$,

where $\sigma_{Z}$ is the square root of the estimation variance (Eq.8).

Thus, the bedrock kriging $B K$, can be expressed as:

$D_{B K}(u, \xi)=[1-\omega(u)] \Theta(u, \xi)+\omega(u) \Phi(u, \xi) L(u)$,

where $\xi$ is the percentiles, in the lognormal pdf $\left(F_{L N}\right)$ of $Z(u)=\ln \left(D_{O K}(u)\right)$ and $\kappa_{O K}(u)=\ln [D(u) / L(u)]$. The corresponding percentiles $\Theta(u, \xi)$ and $\Phi(u, \xi)$ were derived by the inverse lognormal transform:

$\Theta(u, \xi)=F_{L N}^{-1}\left(\xi \mid \mu_{Z}(u), \sigma_{Z}^{2}(u)\right.$

and,

$\Phi(u, \xi)=F_{L N}^{-1}\left(\xi \mid \mu_{\kappa}(u), \sigma_{\kappa}^{2}(u)\right.$

where $F_{L N}^{-1}$ is the lognormal inverse function, and $\left[\mu_{Z}(u), \sigma_{Z}^{2}((u)]\right.$, and $\left[\mu_{\kappa}(u), \sigma_{\kappa}^{2}(u)\right]$, are the ordinary kriging estimates and estimation variance (Eqs.6 and 8). The weights $\omega(u): 0 \leq \omega(u) \leq 1$ are given in Eq.9. 


\section{Poisson's equation and kriging on residuals}

Inverse modelling of the Poisson's equation $(P)$ was applied to fit a two-dimensional parabolic surface to the unknown bedrock topography. Kazhdan et al. (2006) showed that minimizing the differences between the gradient in a scalar function $\chi$, and the related vector field $\boldsymbol{V}$ :

$\min _{\chi}\|\nabla \chi-\boldsymbol{V}\|$,

is equivalent to the Poisson equation:

$\Delta \chi \equiv \nabla \cdot \nabla \chi \equiv \nabla^{2} \chi=\nabla \cdot \boldsymbol{V}$

where $\Delta$ denotes the Laplace operator. The formal procedure described in Kazhdan et al. (2006) can be simplified by replacing the vector field $\boldsymbol{V}$ by a function $\Xi(u), u \in \Omega$ that determine the curvature of the scalar function $\chi(u)$. In this case study, we fitted $\chi(u), u \in \Omega^{\prime}$, where $\Omega^{\prime}$ is the $\emptyset$ vre Eiker study area. Since $\Omega^{\prime}<<\Omega$, we approximated the right-hand side of Eq. 14 to a constant:

$\nabla^{2} \chi=\Xi$

Inverse modelling of $\chi(u)$ means to find a $\Xi$ that minimize the difference between point observations $\chi_{o b s}$ and $\chi_{\text {sim }}$ which is the solution of Eq.15:

$\Xi^{o}=\min \left|\chi_{o b s}\left(u_{i}\right)-\chi_{\text {sim }}\left(u_{i}\right)\right|$,

where $\chi_{\text {sim }}(u)$ is given in Eq.15, and $i=1, \ldots, n$, where $n$ is the number of point observations in the study area. This inverse modelling can be viewed as a trend analysis of the local bedrock topography.

Three types of boundary conditions can be applied to solve Eq.15, namely the: (i) Dirichlet condition, where elevation is given; (ii) Neumann condition, where the gradient of the elevation is given; or (iii) Cauchy condition where a weighted average of (i) and (ii) are given (Gosses et al., 2018; Liu, 2018). Here, in this study, we applied the Dirichlet condition in two slightly different ways. The topography elevation (m a.m.s.l.) can be used directly as boundary conditions: $\chi\left(u_{k}\right)=T\left(u_{k}\right)$; where $R\left(u_{k}\right)=1$. In that case $\chi(u)$ is identical to the local bedrock topography trend $B\left(u \mid \Xi^{o}\right)$, where $\Xi^{o}$ is given by Eg.16. The alternative is to let: $\chi\left(u_{k}\right)=0$ where $R\left(u_{k}\right)=1$. In that case $\chi(u)$ is identical to the local trend of the sediment thickness $D\left(u \mid \Xi^{o}\right)$, and the local trend of the bedrock topography is given by: $B\left(u \mid \Xi^{o}\right)=T(u)-D\left(u \mid \Xi^{o}\right)$.

Inverse modelling on a synthetic data example without any noise in the topography data and with only one point-observation, yields the same numerical solution of the two Dirichlet options. However, there is always some noise in digital topography models, and as the solutions of the Poisson's equation are sensitive to the boundaries, we did inverse modelling of sediment thickness instead of the bedrock topography.

We applied an explicit finite difference numerical scheme of second order to solve Eq.15. This numerical method made implementation of the boundary conditions very simple. An evaluation of the numerical scheme was beyond the scope of this 
study, but no numerical instability was revealed, and high numerical precisions were achieved by feasible consumption of CPU time.

The final step is to perform ordinary kriging of residuals $P K$ :

$X\left(u_{i}\right)=D\left(u_{i} \mid \Xi^{o}\right)-D_{o b s}\left(u_{i}\right)$,

where $D\left(u_{i} \mid \Xi^{o}\right)$ is the results of inverse modelling (Eq.16), and $D_{o b s}\left(u_{i}\right)$ is the point observation, where $i=1, \ldots, n$, and $n$ is the number of observations. In this procedure, we also included the boundary locations $D\left(u_{k}\right)=0$ as additional information, where $u_{k}$ are all the locations of the bedrock outcrops.

\subsection{Percentiles}

Percentiles were derived for $\xi_{p}, p=[0.05,0.1,0.25,0.5,0.75,0.9,0.95]$, in three different ways depending on the methods we applied. For methods based on normal score transform, the percentiles of sediment thickness $D(u ; \xi)$, was achieved by applying the inverse normal score transform $\phi^{-1}$ :

$D(u ; \xi)=\phi^{-1}\left(G\left(Z_{\xi}(u) \mid \hat{Z}_{D}(u), \sigma_{D}(u)\right)\right.$,

where $G(Z)$ denotes the Gaussian cdf of $Z$ in location $u$, which was given by the estimated mean $\hat{Z}_{D}(u)$, and the variance $\sigma_{D}^{2}(u)$ achieved from the kriging equations. Hence, the back transformation $\phi^{-1}$ requires interpolation of the ranked relation between the empirical data $D\left(u_{i}\right)$ and the standard normal variable $Z\left(u_{i}\right)$. The bedrock topography $B(u ; \xi)$ was obtained by inserting 18 in:

$B(u ; \xi)=T(u)-D(u ; \xi)$.

For the $B K$ method, where the lognormal transformation was applied, $Z(u)=\ln (D(u))$, the statistical moments:

$\left.E\{D(u)\}=\hat{D}(u)=\exp [Z \hat{(} u)+\frac{\sigma_{Z}^{2}(u)}{2}\right]$,

and

$295 \operatorname{Var}\{D(u)\}=\sigma_{D(u)}^{2}=\hat{D(u)^{2}}\left[\exp \left(\sigma_{Z}^{2}(u)-1\right)\right]$,

where $Z \hat{(u)}$ and $\sigma_{Z}^{2}(u)$ were derived from Eqs.(6) and (8). In practice the lognormal percentiles were achieved by using the Matlab command logninv (MATLAB, 2017).

For kriging on residuals $P K$, we used the Normal pdf to find the percentiles. That is, we assumed that $X(u) \in N\left(\mu, \sigma_{K}^{2}\right)$, where $\mu$ is the ordinary kriging estimate and $\sigma_{K}^{2}$ is the corresponding estimation variance.

\subsection{Cross-validation}

The modelling results described above, can be expressed as:

$B_{m}\left(u ; \xi_{p}\right)=B\left(u ; \xi_{p} \mid \mathcal{A}\right)$, 
where the subscript $m$ denotes the estimation model $m=[O K, C K, B K, P K], u$ is the estimation grid, $\xi_{p}$ denotes the percentiles, and $\mathcal{A}$ denotes available information.

Three criteria were employed for evaluation of the model uncertainty: the mean absolute error $M_{A E}$, the model accuracy $A_{C}$, and the model precision $P_{C}$ (Goovaerts et al., 2005; Kitterød, 2017). The mean absolute error $M_{A E}$, is the difference between the observed bedrock altitude $B_{o b s}\left(u_{i}\right)$ and the estimated altitude with percentile $\xi_{0.5}$, which in this case is equivalent to the estimated median value:

$M_{A E}=\frac{1}{n} \sum_{i=1}^{n}\left|B_{o b s}\left(u_{i}\right)-B_{m}\left(u_{i} ; \xi_{0.5}\right)\right|$

where $n$ is the number of observations.

The model accuracy $A_{C}$, quantify whether the observed bedrock altitude is within the percentile intervals: $\left[\xi_{0.25}, \xi_{0.75}\right]$. If the observed value is within the interval then $\vartheta=1$, if it is outside, then $\vartheta=0$ :

$A_{C}=\frac{1}{n} \sum_{i=1}^{n} \vartheta\left(u_{i}\right)$

where $n$ is the number of observations.

The model accuracy includes the model uncertainty, which means that in locations with less information and thus larger uncertainty, the model can be accurate (i.e. the estimates are in between the given percentile intervals), but not very precise because of the high uncertainties (which yield large percentile intervals). Thus, a precision criterion is also necessary to include in the evaluation procedure. This can be done by dividing the accuracy by the difference between the upper and lower percentiles, thus the model precision $P_{C}$ reads:

$P_{C}=\sum_{i=1}^{n} \vartheta\left(u_{i}\right) / \Delta \xi$

where $n$ is the number of observations.

For the present study we suggest using the differences between the 0.75 and 0.25 quantiles:

$\Delta \xi=B\left(u_{i} ; \xi_{0.75}\right)-B\left(u_{i} ; \xi_{0.25}\right)$

Thus, the model precision $P_{C}$, should be as high as possible, which means the estimation uncertainty is small. If two modelling results have the same $M_{A E}$ and $A_{C}$, the model with the highest $P_{C}$ is superior.

In addition to the criteria above, we calculated the percentile score of the observations $P_{\text {score }}\left(D_{\text {obs }}\left(u_{j}\right)\right)$ for cross-validation boreholes and sedimentary wells in locations $u_{j}, j=1, \ldots, n$, where $n$ is the number of observations:

$P_{\text {score }}\left(D_{\text {obs }}\left(u_{j}\right)\right)=F\left(u_{i}\right) \mid D_{\text {obs }}\left(u_{j}\right)$,

where $i \neq j=1, \ldots, n$, and $F(u)$ is the cdf of $f(u) \sim N\left(\hat{D}\left(u_{i}\right), \sigma\left(u_{i}\right)\right.$, where $\hat{D}\left(u_{i}\right)$ is the expected sediment thickness (Eqs. 6 and 20) and $\sigma\left(u_{i}\right)$ is the corresponding estimation error (Eqs. 8 and 21). 


\section{Results}

The performance of the suggested methods was evaluated by comparing the solutions with respect to mean absolute error ( $M_{A E}$, Eq.23), model accuracy ( $A_{C}$, Eq.24), and the model precision $\left(P_{C}\right.$, Eq.25). This was first done in a primary crossvalidation procedure by leaving one observation out, and secondly, by jackknife cross-validation. For all cases presented below, we applied a grid resolution $\Delta u=(\Delta x, \Delta y)=(25,25) \mathrm{m}$.

\subsection{Inverse modelling of the Poisson's equation}

We applied the Poisson's equation for trend analysis of the local bedrock topography. This was done by inverse modelling of the constant parameter $\Xi$ in Eq.15. The differences between the modelling results and the observations are usually called the objective function in the literature. In our study, the objective function was identical to the mean absolute error, $M_{A E}$, and the inverse modelling was to find the optimal $\Xi^{o}$, that minimized $M_{A E}$. Since only one constant parameter was involved, this was obtained by incremental stepping of the $\Xi$ factor. This was first done by using all boreholes sampled before 2010, and then by leaving one borehole out (Fig.5). The results show that the minimum $M_{A E}$ was well defined regardless of which borehole that was left out. The minimum $M_{A E}$ was in the range between 2 and $3 \mathrm{~m}$ for all cross-validations, and the optimal parameter $\Xi^{o}$ (Eq.16) was between $4.5 \mathrm{e}-5$ and $6 \mathrm{e}-5$, with an average of 5.5e-5 if all boreholes were included.

\subsection{Semivariograms}

The global GRANADA data were used to calculate experimental semivariograms for ordinary kriging $(O K)$, cokriging $(C K)$ and bedrock kriging $(B K)$. For kriging on residuals $(P K)$ we used GRANADA boreholes located within the study area. For $O K$ and $C K$ the semivariograms were derived from normal score transformed data (c.f. Tab. 3 and 4., case $\mathrm{F}$ in Kitterød (2017)), while semivariograms from logarithmic values are given in (Fig.4 and Tab.1).

\subsection{Primary cross-validation}

The ten boreholes $i=1, \ldots, N$, recorded within the study area before 2010 were applied for primary cross-validation analysis. This cross-validation was performed for observations by leaving one observation out and using the remaining boreholes for conditional modelling of the cdf at the location of the left out borehole: $u_{i, j}, i, j=1, \ldots, N, i \neq j$. For ordinary kriging $(O K)$ only observations of sediment thickness $D\left(u_{i}\right)$, were used for conditional modelling, while for cokriging $(C K)$ and bedrock kriging $(B K)$ the secondary variable $L\left(u_{i}\right)$, was used also in the location of the left out borehole. A digital quaternary map (DQM) was used to identify grid locations $u$ where bedrocks were exposed to the atmosphere $R(u)=1$ or covered by deposits $R(u)=0$ (Fig.6). From $R(u)$ the horizontal distance to the nearest bedrock outcrop $L(u)$ was calculated in all grid points where $R(u)=0$.

The primary cross-validation results show that the $O K$ estimates are close to the spatial average sediment thickness (Fig.7). 
The residuals were calculated based on inverse modelling where all boreholes were involved. Cross-validation by leaving one residual out, with ordinary kriging on the remaining residuals $P K$, gave the best results (Fig.7).

Tab.2 summarize the cross-validation results together with the associated Quaternary deposit at the location of the crossvalidation borehole. The thickest sediment covers are observed in fluvial deposits. The best reproduction was provided by the $P K$ method. In general, the $O K$ results overestimated low values and underestimated high values.

Results from $C K$ and $B K$ also showed an overestimation of low values, but for larger values, these two methods gave better results.

A summary of the cross-validation results by leaving one observation out is given in Tab.3. The $O K$ results gave mean absolute error $M_{A E}$ equal to $6.34 \mathrm{~m}$ for normal score transformed data, and $6.80 \mathrm{~m}$ for lognormal transform. $M_{A E}$ for $C K$ and $B K$ were $6.22 \mathrm{~m}$ and $3.64 \mathrm{~m}$ respectively, and $3.60 \mathrm{~m}$ for inverse modelling of the Poisson's equation $(P)$ and $1.03 \mathrm{~m}$ for kriging on the residuals from the Poisson's equation $(P K)$. Inverse modelling of the Poisson's equation by leaving one borehole out, yielded lower $M_{A E}$; and higher $A_{C}$; and $P_{C}$ than the than $O K$ and $C K$ (Tab.3). These results indicate that methods including a parabolic trend $(P ; P K)$ reproduce the observations better than ordinary kriging, $O K$, cokriging, $C K$, and bedrock kriging, $B K$.

\subsection{Grid percentiles}

Conditional cdfs were calculated in all grid points within the study area for the kriging methods $(O K, C K, B K, P K)$ by using the parameters listed in Tab.1. These cdfs were based on observations of $D(u)$ from boreholes in the study area recorded before 2010. Horizontal distance to nearest bedrock outcrop $L(u)$, was used as secondary information. In addition, we used the surface topography, $T(u)$, from digital elevation models (DEM). The results of the estimated cdfs were presented in terms of percentiles values $\xi_{p}, p=[0.05,0.1,0.25,0.5,0.75,0.9,0.95]$, and these percentiles values were later used for jackknife crossvalidation of boreholes and sedimentary wells recorded after 2010 .

Before presenting the jackknife cross-validation results, some characteristic features in (Fig.8) should be noted. The $O K$ median results $\left(\xi_{0.5}\right)$ of $D(u)$ and $\kappa(u)=\ln [D(u) / L(u)]$ show the local mean of the two variables (Fig.8a and c). The $B K$ estimates (Eqs.10 and 9) are dominated by the recorded sediment depth close to the boreholes, while outside the range of the boreholes, the $B K$ estimates are dominated by $L$. This effect on the $B K$ estmates can be seen at the southwestern part of the image where $L$ is large and where the distance to the nearest boreholes were larger than the range (Fig.8).

The $C K$ results also reflects the spatial structure of the secondary variable $L$, but less prominent than the $B K$ estimates in areas that were distant to the borehole observations. This can be seen in the west-east cross-section that goes through the two boreholes located south of the study area (Fig.9). In general, the uncertainty in the $B K$ estimates were greater than the $C K$ estimates. The $C K$ results however, show greater estimation variances than the $B K$ estimates for locations that were close to the bedrock outcrops, but distant from nearest $D$ observation,

The V-shape of the estimates were evident in the $C K$ and the $B K$ estimates, while solutions of the Poisson's equation on the other hand, had the characteristic U-shape as expected. Kriging on residuals from the Poisson's equations had the smallest estimation variance. 


\subsection{Jackknife cross-validation}

Sedimentary wells and boreholes recorded after 2010 were downloaded and used for independent cross-validation (Fig.2 and 12). Results from the jackknife cross-validation for boreholes and sedimentary wells are given in Tabs. 4 and 5 .

The $O K$ estimates based on normal-score transform and lognormal transform gave similar results: Small sediment thickness were overestimated, and high observations were underestimated (Fig.10). For boreholes the mean absolute error $M_{A E}$, was $3.77 \mathrm{~m}$ for normal score transformed data and $3.73 \mathrm{~m}$ for lognormal transform. Accuracy, $A_{C}$, and precision, $P_{C}$, were also quite similar, but the $O K$ estimates gave highest $A_{C}: 0.60$ for lognormal transform and 0.53 for normal score transform (Tab.6). $B K$ gave $M_{A E}$ of $5.16 \mathrm{~m}$ while $C K$ yielded $4.95 \mathrm{~m}$. The $A_{C}$ was 0.20 for $B K$ and 0.45 for $C K$. Highest $P_{C}$ was obtained from the $B K$ method. For sedimentary wells the $M_{A E}$ was very large for all methods, hence $A_{C}$ and $P_{C}$ was not calculated for these observations (Tab.6). It should be noted that according to the DQM, one of the boreholes (id.58865) was located on exposed bedrock ( $\left.\mathrm{DQM}=130, R\left(u_{o b s}\right)=1\right)$. The observed sediment thickness however, was $D\left(u_{o b s}\right)=7.0 \mathrm{~m}$, thus $R\left(u_{o b s}\right)=0$. This inconsistent input data indicate the uncertainties that exist with respect to location of DQM data and/or exact location of the boreholes. The Poisson's equation gave larger $M_{A E}$ than the kriging methods and lower $P_{C}$, but about the same $A_{C}$ as the bedrock kriging.

\subsection{Percentile score of cross-validation results}

Cumulative histograms of percentile scores (Eq.27) summarize the results of $M_{A E}, A_{C}$ and $P_{C}$ (Fig.11). Perfect estimates yield $P_{\text {score }}=0.5$ with estimation variance equal to zero, which correspond to the bold dashed line in Fig.11. Cross-validation results that overestimated the observations $\left(\hat{D}(u)>D_{\text {obs }}(u)\right.$ had $P_{\text {score }}<0.5$, and vice versa. The cross-validation results by leaving one out, gave $P_{\text {score }} \leq 0.5$ between $30 \%$ and $40 \%$ of the observations for all methods (Fig.11a). Ordinary kriging , cokriging and bedrock kriging had $P_{\text {score }}<0.25$ for about $30 \%$ of the observations for cross-validation results by leaving one out, while between $25 \%$ and $10 \%$ of observations had $P_{\text {score }}>0.25$. Kriging on residuals from the Poisson's equation $(P K)$ had percentile scores between 0.4 and 0.65 for all observations. Percentile scores for the jackknife cross-validation of boreholes showed more overestimation and underestimation for all methods, but with the best performance for the $P K$ method (Fig.11b).

\section{Discussion and conclusions}

In this study we explored the use of public data to estimate the bedrock topography as a continuous function in space. The importance of the bedrock topography in rainfall-runoff modelling has been underlined in many studies before (Genereux et al., 1993a, b; Mulholland, 1993; Hinton et al., 1993; Jencso et al., 2009; Freer et al., 2002; Graham et al., 2010; Graham and McDonnell, 2010; Gabrielli et al., 2012). For runoff response the relation between sediment thickness and bedrock topography is most relevant in areas with sparse sediment cover and low bedrock permeability. Focusing of flow and threshold effects caused by undulations in the bedrock topography, may cause non-linear hysterisis effects in rainfall-runoff relations (Trompvan Meerveld and McDonnell, 2006a; Graham et al., 2010; Graham and McDonnell, 2010; Gabrielli et al., 2012). To improve 
such non-linear effects in hydrology estimates of sediment thickness and bedrock topography need to be included as auxiliary functions. For geotechnical applications, we recommend to include test-drillings as an additional data source for inverse modelling of the Poisson's equation and for conditional point observations in multi-gaussian statistics.

We modelled the estimation uncertainty of the bedrock topography (Eq.1) by using input data from the GRANADA database and geographical information from local study area, Øvre Eiker area, Norway (Fig.2). The purpose was to minimize the uncertainty $\epsilon(u)$ by using digital Quaternary maps (DQM), digital elevation models (DEM) and point observations of the sediment thickness $D\left(u_{i}\right)$ recorded in the GRANADA database (NGU, 2017a). The methods we applied relied on multi-Gaussian statistics which is a simplification of the reality. We also assumed that the information in the DQM could be simplified to a spatial function $R(u)$, where $R(u)=1$ in areas where the bedrock was exposed $(D \simeq 0 \mathrm{~m})$, and $R(u)=0$ in areas covered by deposits $(D>0 \mathrm{~m})$. Below, we discuss briefly some implications of the statistical and geological simplifications we made, but before doing so, it is necessary to comment on some general problems of using public data sources like the GRANADA database, for geostatistical modelling.

\subsection{Clustering and bias of empirical data}

Like most geo- and environmental databases, the GRANADA database contains clustered observations. This is due to the fact that spatial data is usually sampled for a specific purpose, which implies a large number of observations in a few limited areas while most of the sampling domain has less frequent observations. In this case, boreholes and sedimentary wells were drilled in populated locations, which means that there is a high frequency of recordings in urban areas and a limited number in rural and remote areas. Corrections of clustering effects are therefore necessary to perform before statistical inference are undertaken. In this project declustering was done by the moving grid method (Deutsch and Journel, 1998). Declustering of sediment thickness $D(u)$, shows that recordings of small $D(u)$ are more clustered than observations of large $D(u)$. Minor sediment thickness should therefore receive less weights than large sediment thicknesses, and vice versa.

In addition to clustering, the sediment thickness, $D$, recorded in the GRANADA database is most likely biased. The purpose of the GRANADA database was to create useful data to improve management of groundwater resources. A central part of the database was registration and localization of boreholes and wells and not recording of $D$. As boreholes and sedimentary wells are usually drilled for economic reasons, locations with large sediment thickness are usually avoided due to the casing costs. Thus, boreholes may be abandoned for economic reasons if the sedimentary depth is too big. The opposite is true for sedimentary wells. They are usually drilled for domestic water supply, which imply a desire for high water extraction capacity. The water flux into the well is governed by the hydraulic conductivity and the thickness of the water conductive layer. Preferred locations for such wells are therefore areas with large sediment thicknesses. Thus, there are different preferences with respect to $D$ for boreholes and sedimentary wells. The recordings of $D$ are therefore prone to bias, with an over-representation of small $D$ for boreholes and vice versa for sedimentary wells. These preferences have also impact of the location of boreholes and sedimentary wells with respect to horizontal distance to the nearest bedrock outcrop $L$, and the preferred Quaternary deposit.

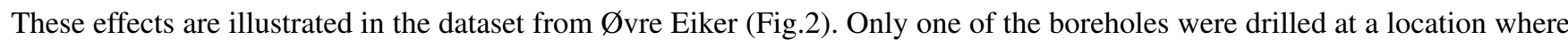
$L>1 \mathrm{~km}$, and 11 of the 25 boreholes had $L<100 \mathrm{~m}$ (Fig.12). Most of the sedimentary wells were also located quite close to 
the bedrock outcrop $(L<100 \mathrm{~m})$, but the sedimentary wells were located where $D$ was expected to be large. All sedimentary wells within the study area were drilled in Fluvial deposits (Tab.5). The nine clustered wells belonged to the same waterwork. The information attached to the well recordings indicate that these wells were located after a seismic survey, which means that a larger area was scanned and the most useful locations were selected. Since the water pumping capacity is proportional to the product of the permeability and the thickness of the sediment, the preferred location had large sediment thicknesses. Thus, if the $D / L$ relation is going to be utilized for modelling of the bedrock topography, other data-sources than GRANADA should be considered. The GRANADA recordings, however, can still be utilized for local conditioning, and because more and more boreholes and wells are registered, the GRANADA database represent a data-source that will increase in value in the coming years.

\subsection{Cross-validation results}

The $O K$ cross-validation results showed that a lumped mean for the whole study area would yield about the same mean absolute error ( $M_{A E}$, Eq.23) as the kriging estimates (Fig.7 and 10). This is not an unexpected result because the magnitude of the small-scale variance $C_{0}$ of $D$ was about $50 \%$ of the total variance $C_{0}+C_{1}$. This fact explains the minor differences between a simple (regression) average and the expected value from kriging. The large $C_{0}$ also explains the differences between the percentile values at the points of observations. If the small-scale variance was zero $C_{0}=0$, then all percentile values would have been equal to the observed value.

The cokriging $(C K)$ results overestimate $D$ for observations below approx. $2 \mathrm{~m}$, and underestimate $D$ for higher values. In general, $C K$ gave lower estimation variance than ordinary kriging $(O K)$ and bedrock kriging $(B K)$, which explains why the accuracy $\left(A_{C}\right.$, Eq.24) may be lower for $C K$ compared to $O K$ and $B K$, while the precision $\left(P_{C}\right.$, Eq.25) on average was higher. The $C K$ results suffer from the same problems as $O K$ and $B K$ because of high $C_{0}$ compared to total variance $C_{1}+C_{0}$. High $C_{0}$ will also affect the relation between $D$ and $L$ and reduces the cross-covariance (Tab.1).

Bedrock kriging $(B K)$ relies on the relation between $D$ and $L$. The observations from the study area shows large variance in the $D / L$ relation (Fig.12). Even though the variance is high, the observations shown in Fig. 12 indicate a physical relation: If $L$ is large, there is no small $D$, and vice versa. This explains the large uncertainties in modelling results if the $D / L$ relation is included in the estimation procedures. These uncertainties were confirmed by the jackknife cross-validation results. It should also be noted that the $D / L$ relation in the global GRANADA database had a similar high variability (Fig.12). The percentile values for the global declustered $D / L$ relation had median value of $D / L=4.7[1.2,18.0] \mathrm{m} / \mathrm{km}$ with 0.25 and 0.75 percentile values in parenthesis (Fig.13). In comparison, data from the study area Øvre Eiker had median $D / L$ of $30 \mathrm{~m} / \mathrm{km}$, which corresponds to the 0.8 percentile value of the global dataset. This indicate that the local $D / L$ estimates should be utilized instead of the global percentiles.

490 Histogram of $D / L$ from the global Granada dataset shows that for $50 \%$ of the boreholes with horizontal distance to bedrock outcrop $L \leq 1 \mathrm{~km}$ had sediment thickness $D \leq 4.7 \mathrm{~m}$ (Fig.13). Non-declustered median value of the same data material gave $D \leq 6.7 \mathrm{~m}$, which shows that there is a clustering of minor $D / L$ values in the GrANADA database. Declustered data shows that $25 \%$ of the wells with $L \leq 1 \mathrm{~km}$ had sediment thickness $D \geq 18.0 \mathrm{~m}$ and $10 \%$ had $D \geq 60.8 \mathrm{~m}$. Corresponding 
values for raw data (not declustered) was $20.2 \mathrm{~m}$ and $54.7 \mathrm{~m}$. For Øvre Eiker, the median value was $D / L=30.7 \mathrm{~m} / \mathrm{km}$. This shows that local conditioning should be used for modelling of bedrock topography if $L$ is used as a secondary variable, which was the motivation for the application of ordinary kriging of $D / L$ in this case study.

The cumulative histograms of $P_{\text {score }}$ (Eq.27) indicate that structures in the bedrock topography were not well captured by the geostatistical methods applied for this case study (Fig. 11). Of that reason, we explored surface reconstruction by using the Poisson's equation as a spatial filter (Eq.15). One motivation for this approach is the U-shaped valleys commonly associated with glacial erosion. A parabolic surface can be adapted to any surface by inverse modelling of parameters in the Poisson's equation. In this case, we argue that the right-hand side of the Poisson's equation can be approximated to a constant because the modelling domain was relatively small $(9 \mathrm{~km} \times 7.2 \mathrm{~km})$. In this context, the parameter $\Xi($ Eq.15) can be interpreted as a source function, which give a parabolic surface with a gradient that is approximated to the expected surface. In this sense, the physical interpretation of $\Xi$ is related to the quality of the local bedrock and the hydrodynamic properties of the glacier ( $v i z$ thickness; flow velocities). For a larger domain, $\Xi$ is not a constant, and a function in space $\Xi(u)$, should be estimated instead. This generalization is left for further studies.

In this case study, we used Dirichlet boundaries for numerical solution of the Poisson's equation. Since the Poisson's equation is very sensitive to Dirichlet boundaries, numerical noise in the boundaries had great impact on the solutions. Here, in this study, we used a regular grid of $25 \times 25 \mathrm{~m}$, which means that the altitude may be irregular and noisy. We also tried to use altitude directly as a Dirichlet boundary, but the numerical solutions were noisy and gave negative sediment depths. These non-physical results were most prominent in locations close to the bedrock outcrop.

These problems were cancelled by adapting the Poisson's surface to the recorded sediment thicknesses instead of the bedrock topography. In that case, the boundary conditions were simply $D\left(u_{k}\right)=0$, where $u_{k}$ is locations where the bedrock outcrops. An alternative boundary condition is to use the gradient of the exposed bedrock altitude as a Neuman condition, or a combination of the Dirchlet and the Neuman condition, which is expressed by the Cauchy boundary (Kazhdan et al., 2006; Liu, 2018). Exploring these alternatives are left for further studies.

A final warning should be included with respect to uncertainties in the digital Quaternary maps (DQM). This is in particular related to the location of the bedrock outcrops. Because all spatial mapping includes uncertainties with respect to exact location, visual inspection of exposed bedrock can be used for quality control. This problem is illustrated in Tab.6, where one of the boreholes (id.58865) had inconsistent information. According to the GRANADA database, the bedrock surface was $7 \mathrm{~m}$ below the ground, but according to the digital Quaternary map, the borehole was located on exposed bedrock. This observation indicates the uncertainty of the spatial information. Depending on the purpose of the work, which determines specifications of accuracy and precision, such kind of spatial uncertainties should be kept in mind.

\subsection{Statistical simplifications}

Modelling of the bedrock topography was first done by conditioning on normal score transformed data, and then secondly by using the lognormal transform. The normal score transform ranks the observations from minimum to maximum and finds the corresponding entries in a standard normal pdf (Deutsch and Journel, 1998). If the empirical dataset does not cover extreme 
values, the normal score transform relies on extrapolations. Hence, the normal score transform is sensitive to the extreme values in the empirical data. The lognormal transform is by definition independent of the empirical data and should therefore yield more robust results with regard to extreme values. The estimation variance, however, usually becomes too large because the expected value, $\hat{D}$, is part of the variance (Eq.21). This drawback explains why the lognormal modelling results had low precision. In this case study, the modelling results based on the normal score transform did not differ very much from the lognormal transformed results. One reason is that even though the univariate pdf by definition is perfect Gaussian, the same is not automatically true for the bivariate pdf. This problem is visualized in Fig.14, where the bivariate normal score transforms of $D$ and $L$ were compared to a synthetic bivariate Gaussian variable with the covariance structure given in Tab.1 for separation distance $h=0 \mathrm{~m}$. As can be seen, the Gaussian character is roughly preserved, but the bivariate pdf is noisy. Since the difference in modelling results were minor between the two transformations, we recommend to apply the simplest and most robust method, which in this case was the lognormal transform.

It should be underlined that the percentiles of the bedrock topography, $B_{u ; \xi_{p}}$, is a smoothed version of the reality. Thus, the percentiles do not represent the bedrock topography itself, but they are used to quantify the estimation uncertainty of the bedrock topography. Since this was the target of our study, we presented the results here in terms of percentiles and not as equally probable realizations. If the spatial variance of the bedrock topography or the sediment thickness plays an important role, then equally probable realizations should be generated. This subject was beyond the scope of the present paper and it is therefore left for further projects.

Multi-Gaussian methods maximize entropy, which implies that the connectivity of extreme values is underestimated (GómezHernández and Wen, 1998). Subsurface canyons for example, which are extremes with respect to topography, will not be captured well by multi-Gaussian modelling. This is a drawback in areas with glacial erosion. Glacial flow may give rise to significant differences in topography over short distances perpendicular to the flow direction, and the longitudinal extent of the valleys may therefore be significant. In geological terms it means that steep and narrow valleys cannot be simulated unconditionally by multi-Gaussian methods. This handicap was a major reason for introducing indicator kriging, which allows different correlation lengths for different threshold values (Deutsch and Journel, 1998; Goovaerts et al., 2005).

\subsection{Geological simplifications}

Geological maps hold vast amounts of information that might be utilized to estimate the bedrock topography. In this study, however, the only information we used was spatial locations of the exposed bedrock, $R(u)=1$, or bedrock covered by sediments, $R(u)=0$. Another relevant question is the relation between the geological setting (i.e. the sediment type) and the bedrock topography. It is common knowledge that the glacial history of the area explains the main character of the landscape. Glacial flow eroded the bedrock and smoothed it's surface. The weight of the glacier suppressed the continental crust, and the isostatic rebound after the melting explains why marine deposits cover the bedrocks in the lower part of the study area. Glacial transgression and retreat explain the deposits of the area, but surface mapping of Quaternary deposits does not usually include thickness of sediments. Some sediment types (in specific areas) usually have significant thickness (like marine sediments), while other kind of deposits usually are patchy and sparse (like avalanches or eroded material). Thus, a relevant project for fur- 
ther research is to match the GRANADA recordings with digital Quaternary maps to find statistical relations between sediment category and sediment thickness. Preliminary results of such investigations are given in Tab.2, Tab.4, and Tab.5. This kind of information might be utilized for future (soft) conditioning of the bedrock topography. For sediment category and sediment thickness $D$, within the study area, it can be noted that boreholes located in fluvial deposits have biggest $D$. If there exists a statistically significant relation between sediment category and sediment thickness, then modelling of $D$ might be improved by using sediment category as an auxiliary function.

By this paper we wanted to draw attention towards modelling of sediment thickness and the associated bedrock topography (Eq.1). We explored the opportunities of combining information from the national well database (GRANADA); digital geological maps; and digital elevation models to reduce the estimation uncertainty.

Multi-Gaussian methods were custom made to handle the complex dataset for this study. This included declustering of the global data; transformation of empirical data; and calculation of variograms and cross-variograms. In this case, the small-scale variance (the nugget) was large compared to the total variance (the sill), which explains why the mean absolute error and the estimation variance were large. The global semivariogram for the sediment thickness had a correlation length of about 2 $\mathrm{km}$, and the cross-semivariogram between the sediment thickness and the horizontal distance to the bedrock outcrop revealed a correlation length of more than $5.5 \mathrm{~km}$ (Tab.1). These correlation lengths indicate that the estimation of the bedrock topography or the sediment thickness can capitalize on observations in the GRANADA database if the distances to the nearest GRANADA recording is less than 2 to $5.5 \mathrm{~km}$ depending on the estimation procedure.

The Poisson's equation was used to estimate the local trend in the sediment thickness. This was done by inverse modelling of a constant parameter in the Poisson's equation. By this approach we fitted a parabolic function to the bedrock topography, which minimized the differences between the point observations and the numerical solutions of the Poisson's equation. We solved the Poisson's equation by using the Dirichlet boundary conditions. In that case, we obtained robust results if we calculated sediment thickness instead of the bedrock topography directly. The reason is that irregularities and uncertainties in the digital elevation model are cancelled if the sediment thickness is calculated instead of the bedrock topography.

Local trend analysis improves the mean absolute error, but the independent (jackknife) cross-validation shows that the estimation uncertainty is large. Because the number of recorded boreholes; wells; and geotechnical test drillings increase for every year, the conditional estimation uncertainties will be reduced. Thus, an important job is to develop simple and robust estimation procedures that can take advantage of the increasing amounts of information. Improved methods for estimation of sediment thickness and bedrock topography are highly recommended in combination with emphasis on quality assurance of practical procedures for field recordings. The mean absolute error, accuracy and precision of the estimation methods depend first and foremost on the quality of the input data.

Author contributions. The main part of the work was done by NOK with significant contributions from ÉL. 
https://doi.org/10.5194/esurf-2019-57

Preprint. Discussion started: 24 October 2019

(C) Author(s) 2019. CC BY 4.0 License.

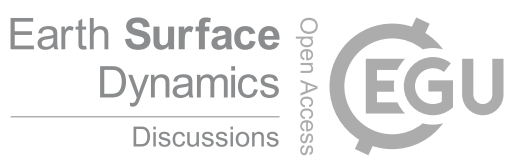

Competing interests. The authors declare that they have no conflict of interest.

Acknowledgements. Thanks to the Geological Survey of Norway (NGU) for providing the dataset; to Norwegian Institute of Bioeconomy 595 Research (NIBIO) for supporting the data harvest; and big thanks to Camille Jouin who did the painstaking work of preparing the data. 


\section{References}

Andersen, T., Trønnes, R.G., Nilsen, O., Larsen, A.O.: Alkaline rocks of the Oslo Rift, SE Norway: A field trip with emphasis on felsic to intermediate intrusive rocks and their associated mineralizations. August 1st to 5th, 2008. Eurogranites 2008/IGCP 510 field trip 2008. Publication of the Department of Geosciences, University of Oslo, 54 p, 2008. Available at: http://folk.uio.no/rtronnes/OsloRift-excursionarticl/Eurogranites-2008-OsloRift.pdf (accessed 06.12.2017).

Bargel, T.H.: Hokksund 1714 I. Kvartærgeologisk kart M 1:50 000, Geological survey of Norway, 1987. Available at: http://www.ngu.no/FileArchive/198/K17141.pdf (accessed 06.12.2017).

Calakli, F. and Taubin, G.: SSD: Smooth signed distance surface reconstruction, Computer Graphics Forum, vol. 30, no. 7, pp. 1993-2002, 2011.

Deutsch, C.: DECLUS: a fortran 77 program for determining optimum spatial declustering weights. Computer \& Geosciences, 15(3):325$332,1989$.

Deutsch, C.V., and Journel, A.G.: GSLIB. Geostatistical Software Library and User's Guide, 2nd. Oxford, New York: Oxford University Press. ISBN 019510015 8, 1998.

Freer, J., McDonnell, J.J, Beven, K.J., Peters, N.E., Burns, D.A., Hooper, R.P., Aulenbach, B., and Kendall, C.: The role of bedrock topography on subsurface storm flow, Water Resour. Res., 38(12), doi:10.1029/2001WR000872, 2002.

Gabrielli, C.P., McDonnell, J.J. and Jarvis, W.T.: The role of bedrock groundwater in rainfall-runoff response at hillslope and catchment scales, Journal of Hydrology 450-451 (2012) 117-133, dx.doi.org/10.1016/j.jhydrol.2012.05.023

Genereux, D. P., Hemond, H.F., and Mulholland, P.J.: Spatial and temporal variability in streamflow generation on the west fork of Walker Branch Watershed, J. Hydrol., 142, 137- 166, 1993a.

615 Genereux, D.P., Hemond, H.F. and Mulholland, P.J.: Use of radon-222 and calcium as tracers in a three-end-member mixing model for streamflow generation on the West Fork of Walker Branch Watershed. J. Hydrol., 142:167-211, $1993 \mathrm{~b}$.

Gómez-Hernández, J.J., and Wen, X.-H.: To be or not to be multi-Gaussian? A reflection on stochastic hydrogeology, Advances in Water Resources, Vol. 21, No. 1, pp. 47-61, 1998

Goovaerts, P., AvRuskin, G., Meliker, J., Slotnick, M., Jacquez, G., and Nriagu, J.: Geostatistical modeling of the spatial variability of arsenic in groundwater of southeast Michigan, Water Resour. Res., 41, W07013, doi:10.1029/2004WR003705, 2005.

Gosses, M., Nowak, W., Wohling, T.: Explicit treatment for Dirichlet, Neumann and Cauchy boundary conditions in POD-based reduction of groundwater models, Advances in Water Resources, Vol. 115, pp. 160-171, doi.org/10.1016/j.advwatres.2018.03.011

Graham, C.B., Woods, R.A., and McDonnell, J.J.: Hillslope threshold response to rainfall: (1) A field based forensic approach, Journal of Hydrology 393 (2010) 65-76, doi:10.1016/j.jhydrol.2009.12.015.

Graham, C.B., and McDonnell, J.J.: Hillslope threshold response to rainfall: (2) Development and use of a macroscale model, Journal of Hydrology 393 (2010) 77-93, doi:10.1016/j.jhydrol.2010.03.008.

Hinton, M. J., Schiff S. L., and English M. C.: Physical-properties governing groundwater-flow in a glacial till catchment, J. Hydrol., 142, 229-249, 1993.

Hopp,L., and J.J. McDonnell, J.J.: Connectivity at the hillslope scale: Identifying interactions between storm size, bedrock permeability, slope angle and soil depth. Journal of Hydrology 376 (2009) 378-391, doi:10.1016/j.jhydrol.2009.07.047.

Isaaks, H., and Srivastava, R.M.: An Introduction to Applied Geostatistics, 1989. 
https://doi.org/10.5194/esurf-2019-57

Preprint. Discussion started: 24 October 2019

(c) Author(s) 2019. CC BY 4.0 License.

Jencso, K.G., McGlynn, B. L., Gooseff, M.N., Steven M. Wondzell, S. M., Bencala, K. E., and Marshall, L.A.: Hydrologic connectivity between landscapes and streams: Transferring reach- and plot-scale understanding to the catchment scale, Water Resour. Res. (45) W04428, doi:10.1029/2008WR007225, 2009.

Journel, A.G., and Huijbregts, Ch.J.: Mining geostatistics, 4th ed. Academic Press, London, 1989.

Kazhdan, M., Bolitho, M., and Hoppe H.: Poisson Surface Reconstruction. In: Polthier, K., and Sheffer, A. (ed.), Eurographics Symposium on Geometry Processing, 2006.

Kitterød, N.-O.: Estimating unconsolidated sediment cover thickness by using the horizontal distance to a bedrock outcrop as secondary information, Hydrol. Earth Syst. Sci., 21, 4195-4211, https://doi.org/10.5194/hess-21-4195-2017, doi:10.5194/hess-21-4195-2017, 2017.

Liu, C.-S.: Fast solving the Cauchy problems of Poisson equation in an arbitrary three-dimensional domain Computer Modeling in Engineering and Sciences 114(3), doi: 10.3970/cmes.2018.114.351, 2018

Lovdata: Norwegian law on public reporting duties related to wells, probe drillings and boreholes. (In Norwegian: Forskrift om oppgaveplikt ved brønnboring og grunnvannsunders $\varnothing$ kelser), 1996. https://lovdata.no/dokument/SF/forskrift/1996-11-19-1066 (accessed 06.12.2017).

MATLAB, The MathWorks Inc., Release 2017.

645 Mulholland, P.J.: Hydrometric and stream chemistry evidence of three storm flowpaths in Walker Branch Watershed, Journal of Hydrology, 151, 291-316, 1993.

Myers,D.E.: Matrix Formulation of Co-Kriging, Math. Geol., 14(3) pp249-257, 1982.

NGU: Geological Survey of Norway, GRANADA database, 2017a. http://geo.ngu.no/kart/granada/ (accessed 05.12.2017).

NGU: Bedrock - National bedrock database, 2017b. http://geo.ngu.no/kart/berggrunn (for English: http://geo.ngu.no/kart/berggrunn_mobil (accessed 05.12.2017).

NGU: Superficial deposits - National Database, 2017c. http://geo.ngu.no/kart/losmasse/ (for English: http://geo.ngu.no/kart/losmasse_mobil) (accessed 05.12.2017).

Omre, H.: The variogram and its estimation. In Verly, G. et al. (ed.), Geostatistics for Natural Resources Characterization, 1, pp 107-125, 1984. Reidel, Dordrecht, Holland.

Pyrcz, M.J., and Deutsch, C.V.: Declustering and debiasing. In: Searston, S. (ed.): Newsletter 19, October 2003, Geostatistical Association of Australasia, Melbourne, 2003. Available at: https://www.researchgate.net/publication/228427948_Declustering_and_debiasing (accessed 29.11.2017).

Terink, W., Hurkmans, R.T.W.L., Torfs, P.J.J.F., Uijlenhoet, R.: Evaluation of a bias correction method applied to downscaled precipitation and temperature reanalysis data for the Rhine basin, Hydrol. Earth Syst. Sci., 14, 687-703, www.hydrol-earth-syst-sci.net/14/687/2010/, doi:10.5194/hess-14-687-2010, 2010.

Tromp-van Meerveld, H.J., and McDonnell, J.J.: Threshold relations in subsurface stormflow: 1. A 147-storm analysis of the Panola hillslope, Water Resour. Res. (42) W02410, doi:10.1029/2004WR003778, $2006 \mathrm{a}$.

Tromp-van Meerveld, H.J., and McDonnell, J.J.: Threshold relations in subsurface stormflow: 2. The fill and spill hypothesis. Water Resour. Res. (42) W02411, doi:10.1029/2004WR003800, 2006b

Wolff, M.A., Isaksen, K., Petersen-Øverleir, A., Ødemark, K., Reitan, T. and Brækkan, R.: Derivation of a new continuous adjustment function for correcting wind-induced loss of solid precipitation: results of a Norwegian field study, Hydrol. Earth Syst. Sci., 19, 951-967, doi:10.5194/hess-19-951-2015, 2015 


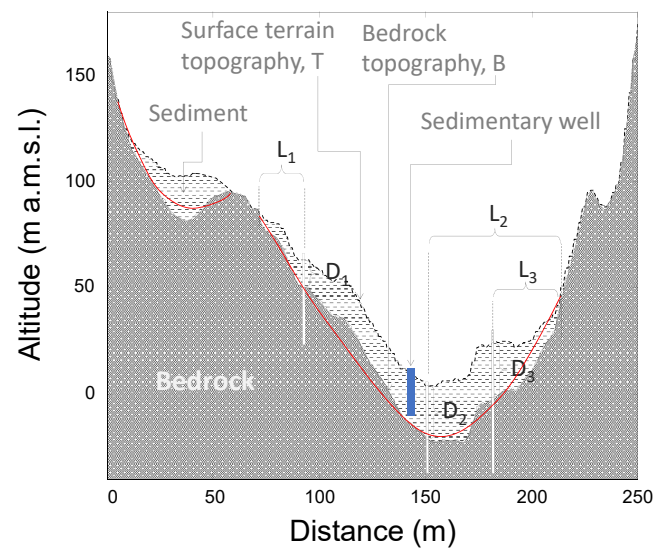

Figure 1. Two principles for including a local trend in estimation of the bedrock topography. Firstly, by using the relation between the sediment thickness $D\left(u_{i}\right)$, and the horizontal distance to the nearest bedrock outcrop $L\left(u_{i}\right)$, where $u_{i}$ are the locations of the observations. Secondly, by fitting a parabolic curve to the bedrock topography (red curve) by solving the Poisson's equation. Boreholes (white rectangles) penetrate the sediments into the bedrock, while sedimentary wells (blue rectangle) does not penetrate into the bedrock. The figure is modified from Kitterød (2017).

Table 1. Covariance and cross-covariance model parameters ${ }^{1}$ used in ordinary kriging $(O K)$, co-kriging $(C K)$, bedrock kriging $B K$, and kriging on residuals from the Poisson's equation $(P K)$. The observations were either normal score $\left(^{*}\right)$ or lognormal transformed $\left(^{\prime}\right)$.

\begin{tabular}{|c|c|c|c|c|c|}
\hline Case & & $C_{0}$ & $C_{1}$ & $a[m]$ & $\alpha$ \\
\hline & $C_{D D}$ & 0.077 & 0.726 & 2371 & 1.00 \\
\hline$O K^{*}$ & $C_{D L}$ & 0.003 & 0.207 & 2402 & 1.01 \\
\hline \multirow[t]{2}{*}{$C K^{*}$} & $C_{L D}$ & 0.003 & 0.207 & 2402 & 1.01 \\
\hline & $C_{L L}$ & 0.007 & 0.638 & 5865 & 1.02 \\
\hline$O K^{\prime}$ & $C_{D}$ & 0.35 & 0.750 & 2100 & 1.0 \\
\hline$B K^{\prime}$ & $C_{\kappa}$ & 0.002 & 0.720 & 8000 & 1.0 \\
\hline$P K$ & $C_{X}$ & 5 & 9 & 4000 & 1.0 \\
\hline \multicolumn{6}{|c|}{$\begin{array}{l}\text { 1) } C_{m n}(h)=C_{0}+C_{1}-\gamma\left(h_{m n}\right) \text {, and } \\
\gamma\left(h_{m n}\right)=C_{0}+C_{1}\left[1-\exp \left(\beta\left(\frac{h}{a}\right)^{\alpha}\right)\right] \text {, where } m n \\
\text { indicate either normal score or lognormal transformed sediment } \\
\text { thickness } D \text {, or the horizontal distance to bedrock outcrop } L \text {. } \\
\kappa=\ln [D / L] \text {, and } X \text { is the residuals between Poisson's } \\
\text { equation and observations (Eq.17). The practical range } \beta= \\
\log (0.05) \text {, for all modells. }\end{array}$} \\
\hline
\end{tabular}




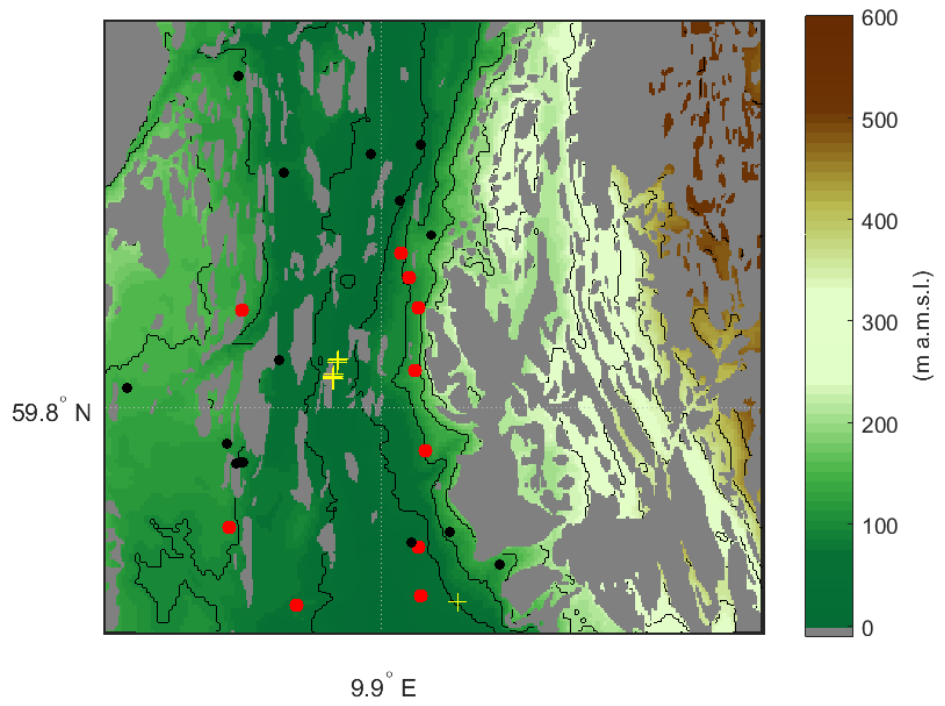

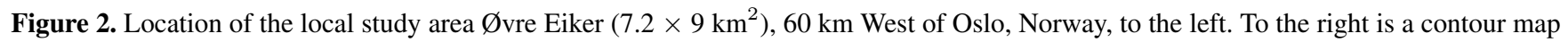
of Øvre Eiker surface topography; locations of boreholes registered before 2010 (red dots); boreholes registered after 2010 (black dots); and sedimentary wells (yellow plus sign). Grey color indicates areas with bedrock outcrops. 

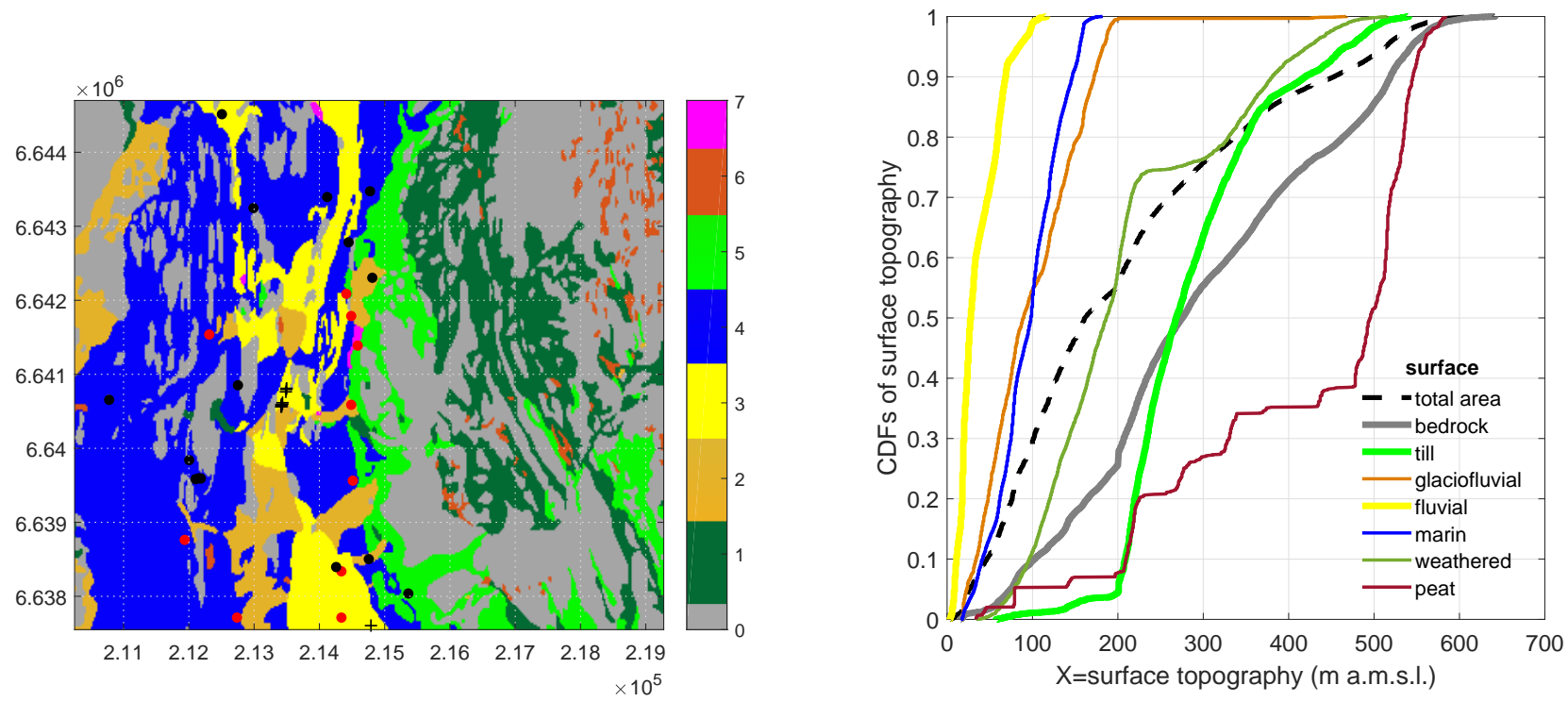

Figure 3. Digital Quaternary Maps of Øvre Eiker (left figure) with boreholes registered before 2010 (red dots), and after 2010 (black dots), and sedimentary wells (black plus sign). The hypsographic curves (right figure) indicate the distribution of surface cover as a function of altitude (m a.m.s.1.). The area fraction of the different surface categories was: 0) bedrock (36.9\%); 1) till and moraine sediments (12.9\%); 2) glaciofluvial sediments $(6.2 \%) ; 3)$ fluvial sediments $(6.9 \%) ; 4)$ marine sediments $(27.1 \%)$; 5) weathered material and avalanches $(8.1 \%)$; 6$)$ peat and swaps $(1.6 \%) ; 7)$ anthropogenic material $(0.14 \%)$. Percentages of the total area are given in the parentheses.
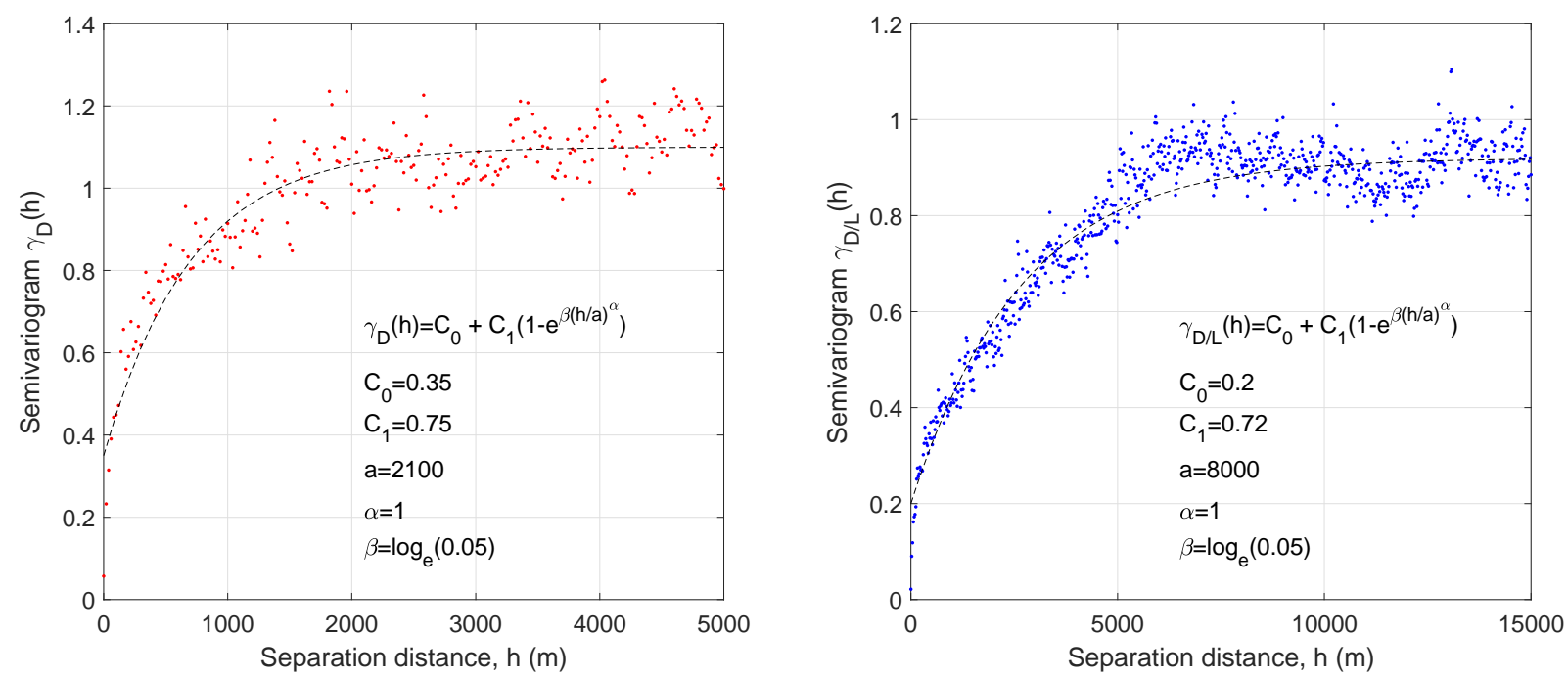

Figure 4. Semivariograms for $\ln (D)$ to the left, and $\kappa=\ln (D / L)$ to the right, $D$ is the sediment thickness, and $L$ is the horizontal distance from the location of the borehole to the location of the nearest bedrock outcrop. 


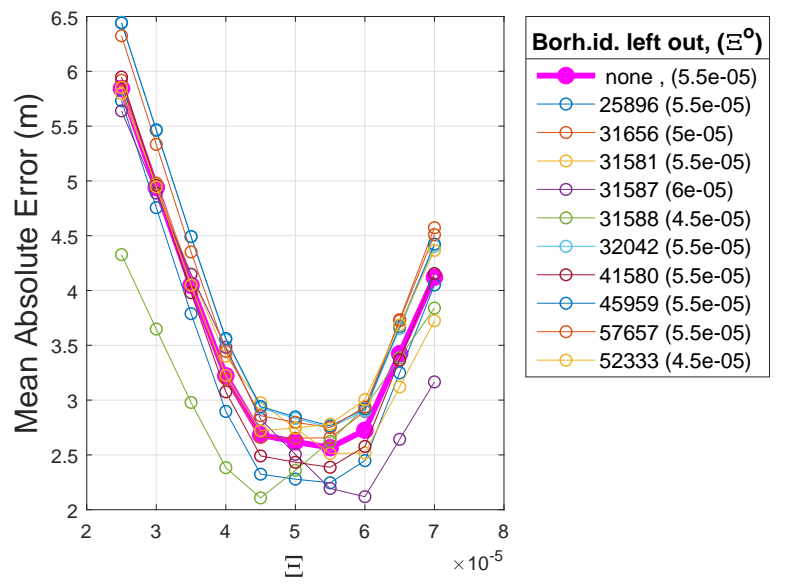

Figure 5. Inverse modelling of the Poisson's equation (Eq.16) by incremental stepping of the constant $\Xi$ factor in Eq.15. The inverse modelling results are shown where all local boreholes are included (magenta), and then by successively leaving one borehole out. The boreholes left out are indicated by the GRANADA borehole id. in the legend. A minimum of mean absolute error is obtained for $\Xi^{o}$ in the interval $\Xi^{o}=[4.5 \mathrm{e}-5,6 \mathrm{e}-5]$. With all then wells included, the optimal solution is $\Xi^{o}=5.5 \mathrm{e}-5$ (c.f. right hand side of the legend).

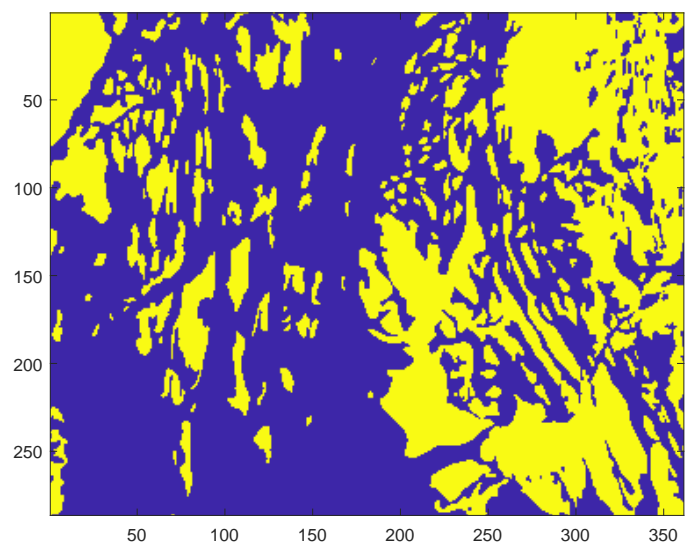

Øvre Eiker.

Exposed bedrock: $F(u)=1$ if $D(u)=0$

Bedrock covered: $F(u)=0$, if $D(u)>0$

Figure 6. Gridded map for $\emptyset$ vre Eiker (c.f. Fig.2) showing areas with bedrock outcrops $F(u)=1 ; D(u)=0$ and areas where the bedrock is covered by deposits $F(u)=0 ; D(u)>0 ;$. Grid resolution: $\Delta u=(\Delta x, \Delta y)=(25,25) \mathrm{m}$. 


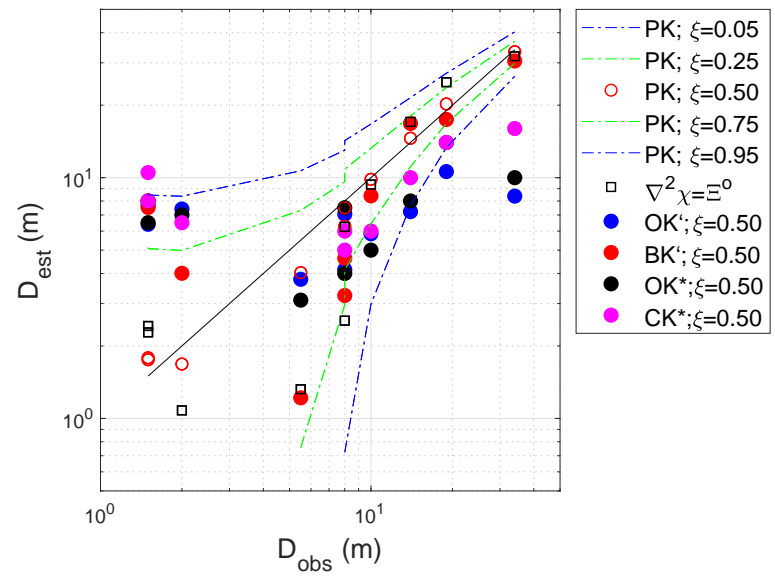

Figure 7. Cross-validation by leaving one observation out of boreholes recorded before 2010. Optimal solutions of the Poisson's equation are indicated by black squares (Eqs.15 and 16). Cross-validation of kriging on residuals (Eq.17) of the Poisson's equation ( $P K)$, are shown for different percentiles $\xi$. Upper and lower percentiles $\xi=[0.05,0.95]$ as blue dashed line, and $\xi=[0.25,0.75]$ as green dashed line. The median values, $\xi=[0.50]$, are shown as circles, with open red circles for the $P K$ solutions, blue and black solid circles for ordinary kriging $(O K)$, red solid circle for bedrock kriging $(B K)$, and magenta solid circles for cokriging $(C K)$. Results based on lognormal transformed observations were indicated by ${ }^{\prime}$, and normal score transformed observations by $*$. The solid line indicates a 1:1 relation between estimates and observations. 

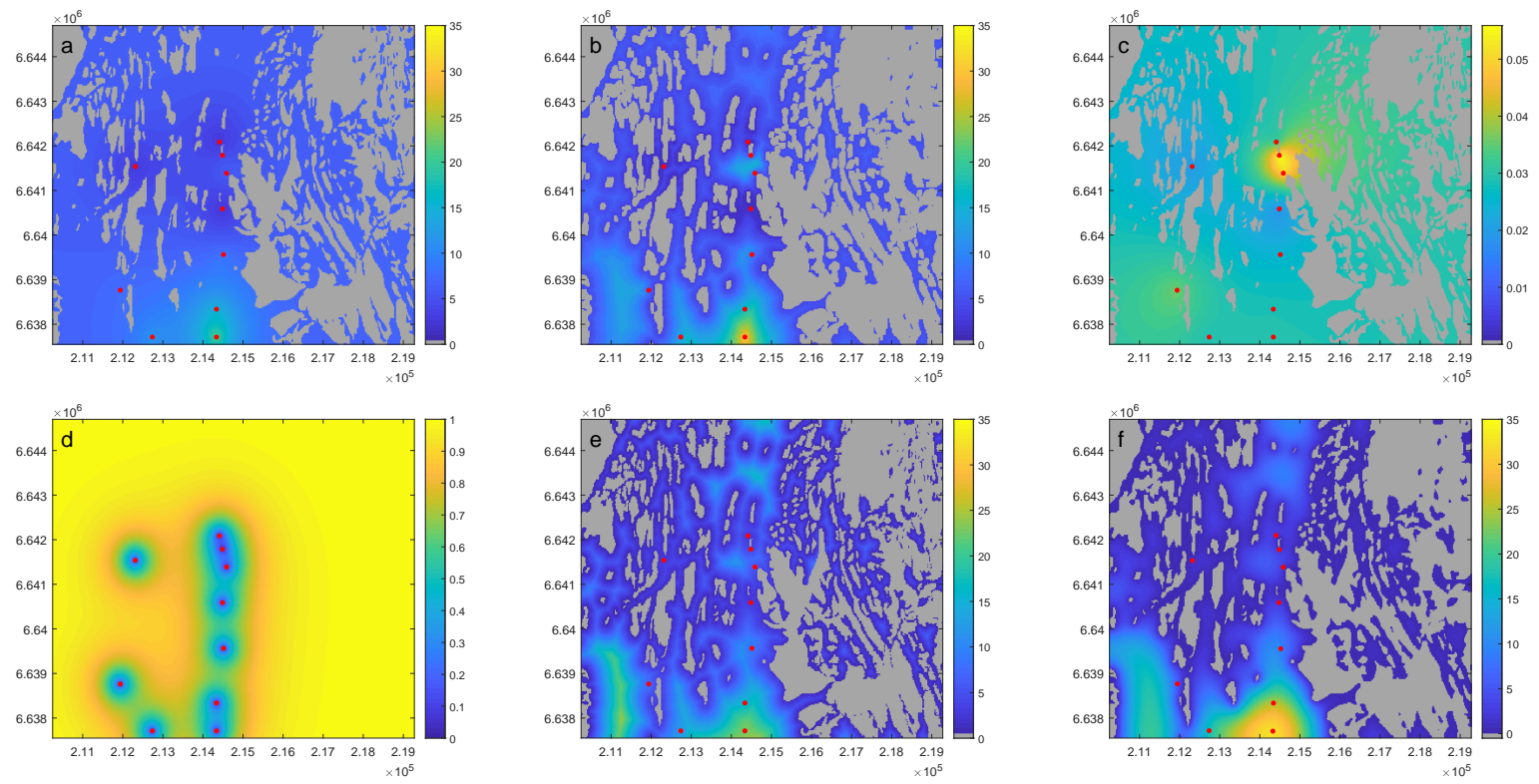

Figure 8. Images of the $\emptyset$ vre Eiker area showing estimated percentile values $\xi=0.5$ of sediment thickness $D[m] ; \kappa=\log (D) / \log (L)[-]$, where $L[m]$ is the horizontal distance to the nearest bedrock outcrop; and bedrock kriging weights $\omega[-]$ (Eq.9). a) $D(u ; \xi=0.5)$ by ordinary kriging $(O K)$; b) $D(u ; \xi=0.5)$ by cokriging $(C K)$; c) $\kappa(u ; \xi=0.5)$ by ordinary kriging $(O K)$; d $\omega(u)$, Eq.9; e) $D(u ; \xi=0.5)$ by bedrock kriging $(B K)$; f) $D\left(u \mid \Xi^{*}\right)$ Eq. 15 . 

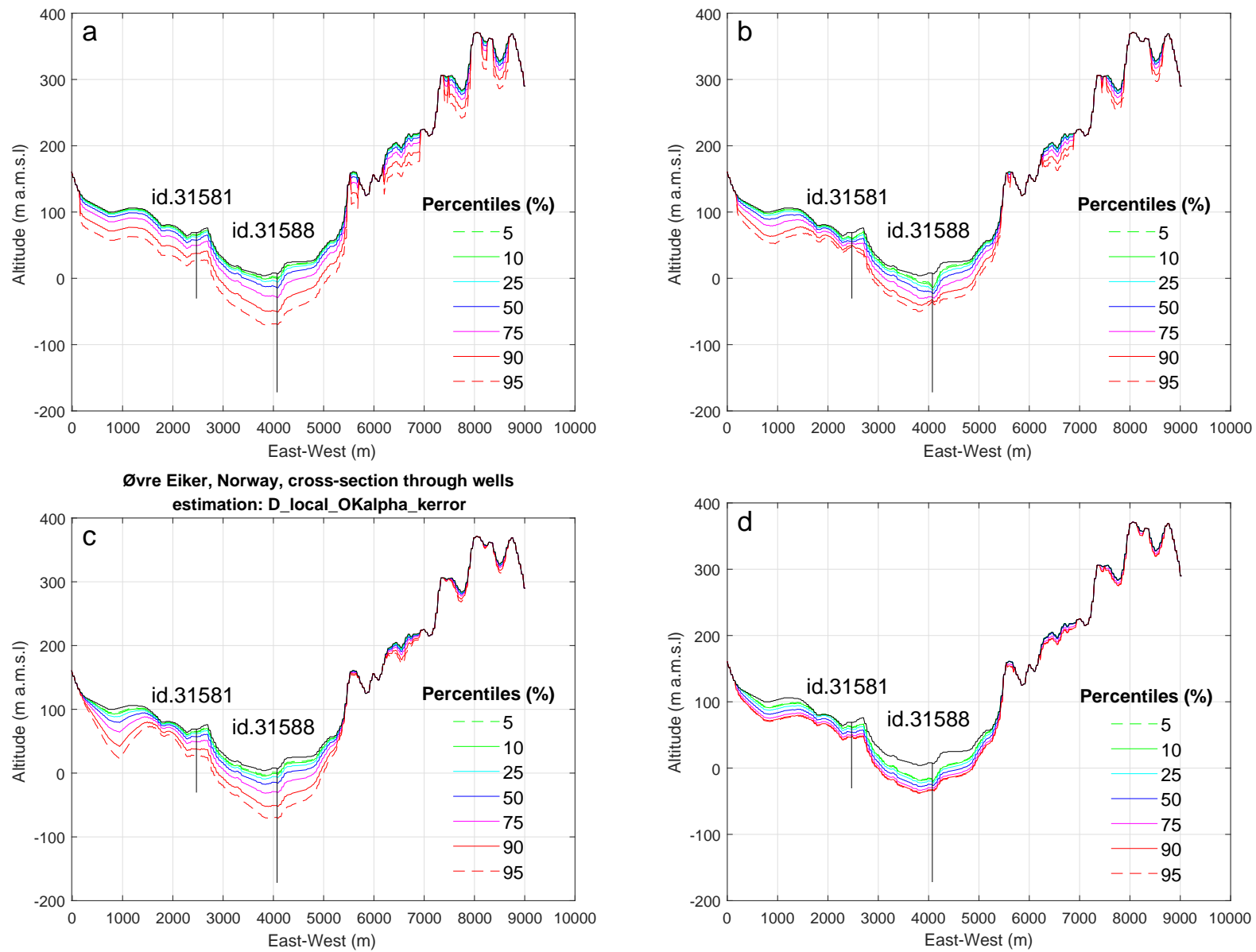

Figure 9. East-West cross-sections of bedrock topography shown as percentile values for a) ordinary kriging $O K$; b) cokriging $C K$; c) bedrock kriging $B K$; and d) kriging on residuals from the optimal solution of the Poisson's equation $P K$. The cross-sections go through the two southern most boreholes shown in Fig.2. 


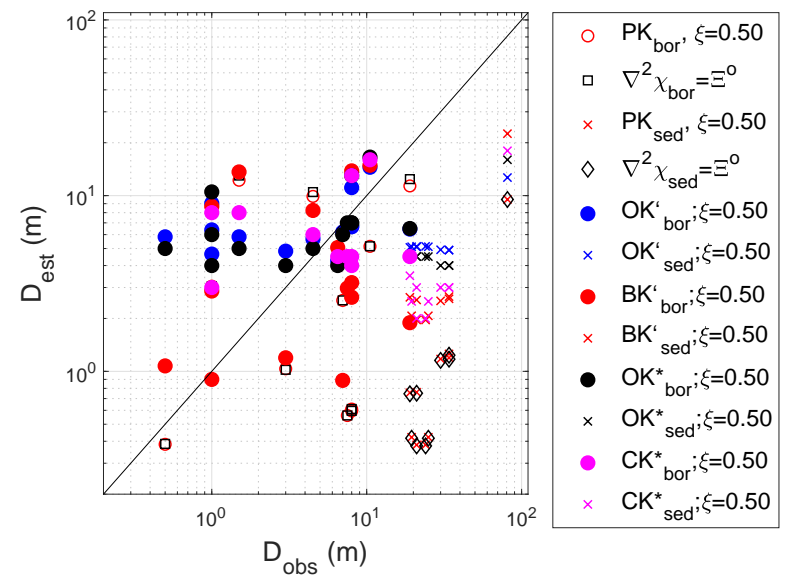

Figure 10. Jackknife cross-validation results of boreholes (bor) and sedimentary wells (sed) recorded after 2010 (c.f. Fig.2). $\nabla^{2} \chi_{b o r}=\Xi^{o}$ indicate optimal solutions of the Poisson's equation, $P K$ is kriging on residuals from the optimal Poisson's equation, $O K$ is ordinary kriging, $B K$ is bedrock kriging, and $C K$ is cokriging.
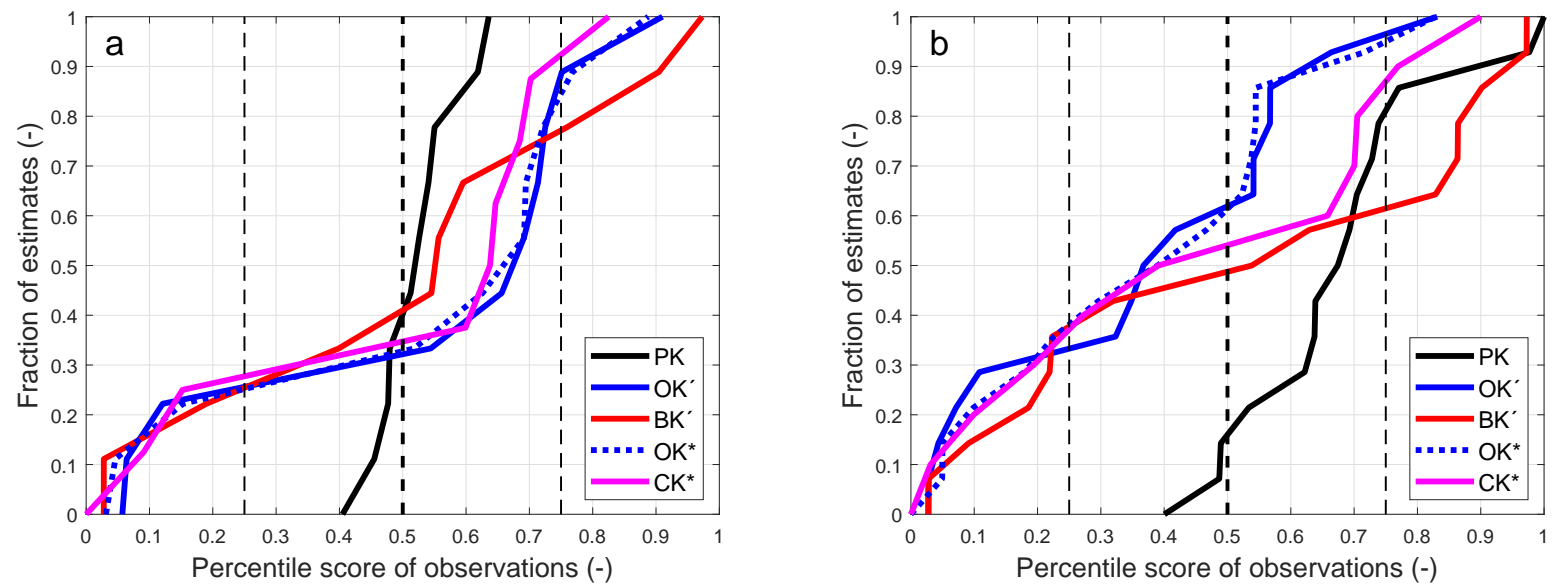

Figure 11. Cumulative histograms of percentiles scores (Eq.27) from cross-validation of borehole observations. The figure on the left-hand side (a) shows cross-validation results by leaving one observation out. The observations used for this cross-validation were boreholes recorded before 2010. The right-hand side (b) shows jackknife cross-validation results, i.e. cross-validation on independent observations recorded after 2010. The black solid curves indicate kriging on residuals from the optimal Poisson's equation ( $P K)$, (Eqs.15 and 16). Blue solid and dotted lines show results from ordinary kriging $O K$. Red lines show bedrock kriging results $B K$. Magenta lines indicate cokriging results $C K$. The superscripts ', and $*$ indicate that calculations were done on lognormal or normal score transformed data. Black dashed lines indicate cross-validation results corresponding to $[0.25,0.5,0.75]$ percentile scores with zero estimation variance. 


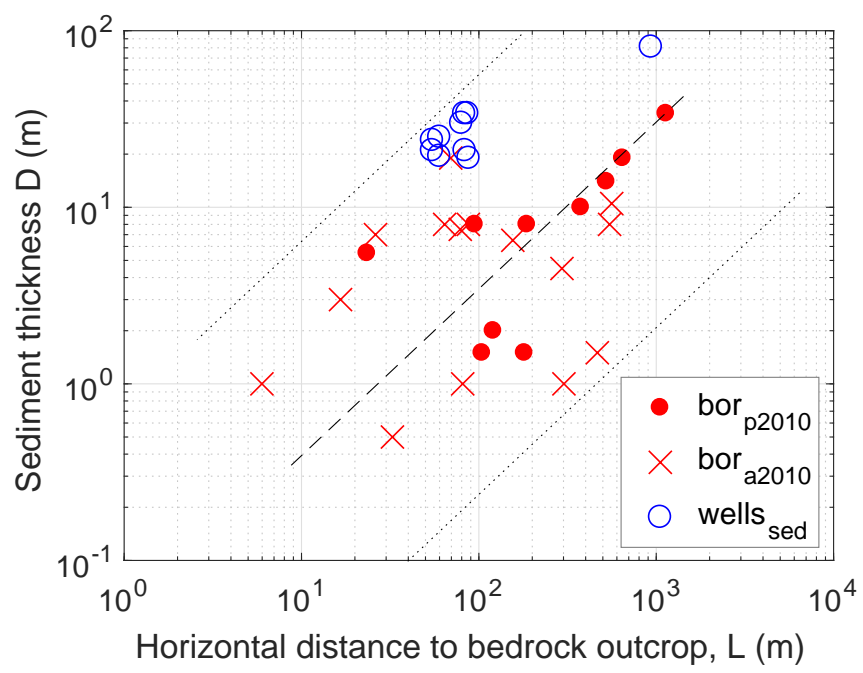

Figure 12. GRANADA recordings of boreholes and sedimentary wells in the Øvre Eiker study area (c.f. Fig.2). The figure shows the relation between horizontal distance to nearest bedrock outcrop $L$, and sediment thickness $D$ for boreholes that penetrate the deposits and goes into the bedrock. For sedimentary wells (blue circles) the sedimentary thickness is not recorded, only the length of the well, thus for these wells $D$ is equal to the length of the well, which means that the true sediment thicknesses for these wells are either equal to $D$ shown on the figure or larger. Boreholes recorded before 2010 were used for cross-validation by leaving one well out. After this primary cross-validation, percentiles were conditioned on all boreholes recorded before 2010. Boreholes recorded after 2010 (red crosses) and sedimentary wells (blue circles) were used for jackknife cross-validation. 


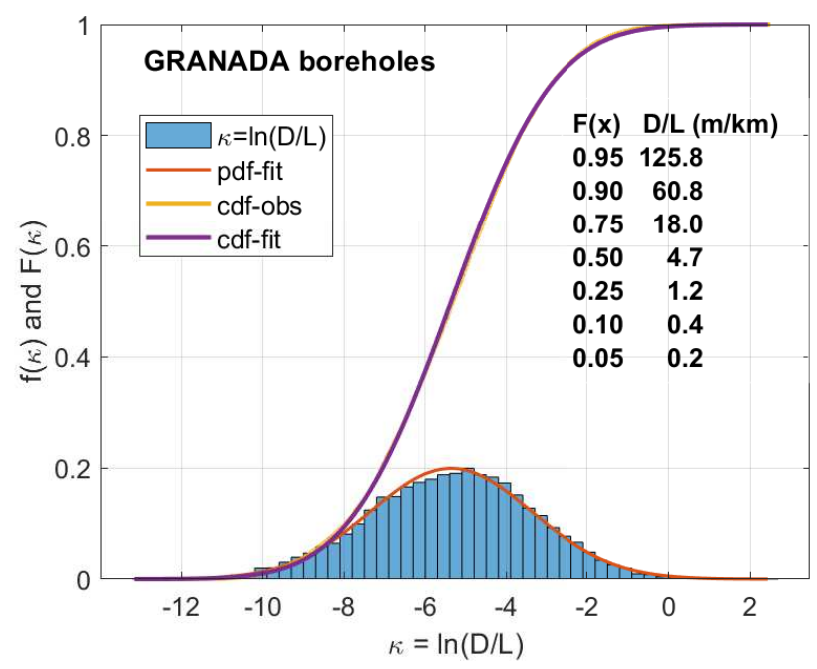

Figure 13. Histogram and cumulative probability density function (cdf) of $\kappa=\ln (D / L)$ for the global GRANADA data base. The histogram (blue) and the cdf-obs (yellow) are derived from declustered observations, while the pdf-fit (brown) and the cdf-fit (purple) are fit to a Gaussian pdf. The table was derived from inverse lognormal percentiles.
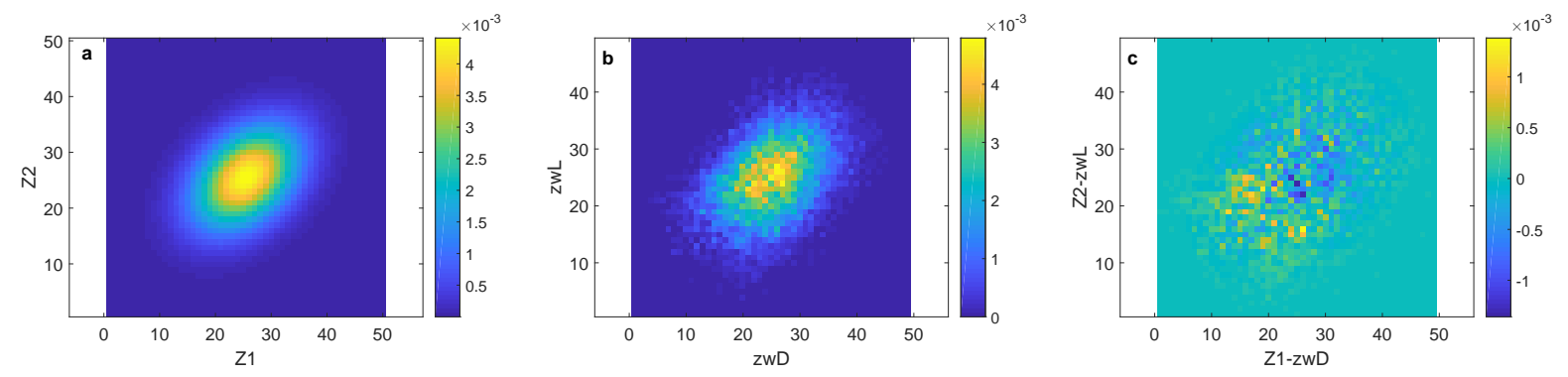

Figure 14. Synthetic multi-Gaussian probability density function to the left (a) normal score transformed sediment thickness $D$ and horizontal distance to nearest bedrock outcrop $L$ in the middle (b), and the difference between the synthetic pdf and the empirical to the right (c). The synthetic pdf was generated with zero mean and covariance function equal to the empirical data for separation distance $h=0$ (c.f. Tab.1). 
Table 2. Cross-validation by leaving one borehole out. The results show estimated sediment depths $D_{\text {obs }}$, for percentile $\xi=0.5$. The boreholes were recorded before 2010, and the identification number (id.) corresponds to the id. in the GRANADA database (NGU, 2017a). $D_{\text {obs }}$ and $L_{o b s}$ are the measured sediment depths, and the horizontal distances to nearest bedrock outcrop. The results are given for: ordinary kriging $\left(D_{O K}\right)$, cokriging $\left(D_{C K}\right)$, bedrock kriging $\left(D_{B K}\right)$, Poisson modelling of the sediment depths $\left(D_{P}\right)$, and by ordinary kriging of the residuals between observations and the Poisson modelling sediment depths ( $D_{P K}$. The superscripts indicate that the modelling was based on observations that was either normal score transformed $\left(^{*}\right)$ or lognormal transformed $\left(^{\prime}\right)$. Identification of the deposits was taken from the digital Quaternary map (DQM, c.f. table footnote).

\begin{tabular}{cccccccccc}
\hline id. & $D_{o b s}$ & $L_{o b s}$ & $D_{O K}^{*}$ & $D_{C K}^{*}$ & $D_{O K}^{\prime}$ & $D_{B K}^{\prime}$ & $D_{P}$ & $D_{P K}$ & DQM \\
\hline 45959 & 1.5 & 115.5 & 6.5 & 10.5 & 6.4 & 7.5 & 2.3 & 1.9 & 43 \\
32042 & 1.5 & 176.1 & 8.0 & 8.0 & 7.7 & 8.0 & 2.4 & 1.9 & 20 \\
57657 & 2.0 & 126.1 & 7.0 & 6.5 & 7.4 & 4.0 & 1.1 & 1.6 & 43 \\
41580 & 5.5 & 32.2 & 3.1 & $\mathrm{NaN}$ & 3.8 & 1.2 & 1.3 & 3.7 & 50 \\
25896 & 8.0 & 93.9 & 4.0 & 5.0 & 4.1 & 3.2 & 2.6 & 5.8 & 120 \\
31656 & 8.0 & 181.1 & 7.5 & 6.0 & 7.1 & 4.6 & 6.3 & 7.3 & 41 \\
52333 & 10.0 & 363.6 & 5.0 & 6.0 & 5.8 & 8.4 & 9.4 & 9.7 & 41 \\
31581 & 14.0 & 520.7 & 8.0 & 10.0 & 7.2 & 16.8 & 17.0 & 15.0 & 42 \\
31587 & 19.0 & 649.5 & 14.0 & 14.0 & 10.6 & 17.4 & 24.9 & 21.2 & 50 \\
31588 & 34.0 & 1129.0 & 10.0 & 16.0 & 8.4 & 30.5 & 31.9 & 32.9 & 50 \\
\hline
\end{tabular}

NaN (Not a Number) means that no estimates were provided.

Digital Quaternary map (DQM) deposits identification:

20 Glaciofluvial sediments.

41 Ocean and coastal sediments, coherent, often great thickness.

42 Marin beach sediments, continuous.

43 Ocean, sea and beach sediments, patchy or thin cover over bedrock.

50 Fluvial (River and stream sediments).

120 Anthropogenic deposits. 
https://doi.org/10.5194/esurf-2019-57

Preprint. Discussion started: 24 October 2019

(c) Author(s) 2019. CC BY 4.0 License.

Table 3. Summary of cross-validation by leaving one borehole out. Results from: Ordinary kriging $(O K)$, cokriging $(C K)$, bedrock kriging $(B K)$ and the Poisson equation $(P)$ with optimal load parameter estimated by leaving one observation out. Kriging on residuals between observations and the Poisson equation $(P K)$ were done for the Poisson solution where the optimal parameter was estimated based on all boreholes. The superscripts indicate either normal score transform $\left(^{*}\right)$ or lognormal transform $\left({ }^{\prime}\right)$ of observations. The Poisson solutions were done on original data.

\begin{tabular}{lcccccc}
\hline & $O K^{*}$ & $C K^{*}$ & $O K^{\prime}$ & $B K^{\prime}$ & $P$ & $P K$ \\
\hline$M_{A E}$ & 6.34 & 6.22 & 6.80 & 3.64 & 3.60 & 1.03 \\
$A_{C}$ & 0.50 & 0.56 & 0.50 & 0.40 & 0.50 & 0.80 \\
$P_{C}$ & 0.56 & 1.75 & 0.55 & 0.57 & 1.31 & 1.57 \\
\hline
\end{tabular}

$M_{A E}$ : Mean absolute error, Eq.23.

$A_{C}$ : Accuracy, Eq.24.

$P_{C}$ : Precision, Eq.25. 
Table 4. Jackknife cross-validation of boreholes recorded after 2010. The id. is the borehole number in the GRANADA database (NGU, 2017a). See Tab.2 for explanation of table heading and abbreviations. Identification of the deposits (c.f. footnote) was taken from the digital Quaternary map (DQM).

\begin{tabular}{cccccccccc}
\hline id. & $D_{\text {obs }}$ & $L_{\text {obs }}$ & $D_{O K}^{*}$ & $D_{C K}^{*}$ & $D_{O K}^{\prime}$ & $D_{B K}^{\prime}$ & $D_{P}$ & $D_{P K}$ & DQM \\
\hline 87691 & 0.5 & 32.6 & 5.0 & $\mathrm{NaN}$ & 5.8 & 1.1 & 0.74 & 0.75 & 43 \\
26947 & 1.0 & 301.7 & 10.5 & 8.0 & 9.0 & 8.7 & 11.4 & 11.5 & 70 \\
29311 & 1.0 & 81.1 & 4.0 & 3.0 & 4.6 & 2.9 & 1.9 & 1.9 & 43 \\
86672 & 1.0 & 6.0 & 6.0 & $\mathrm{NaN}$ & 6.4 & 0.9 & 0.12 & 0.12 & 41 \\
31223 & 1.5 & 465.5 & 5.0 & 8.0 & 5.8 & 13.6 & 8.0 & 8.18 & 41 \\
65892 & 3.0 & 16.6 & 4.0 & $\mathrm{NaN}$ & 4.8 & 1.2 & 0.11 & 0.10 & 41 \\
71404 & 4.5 & 294.1 & 5.0 & 6.0 & 5.7 & 8.2 & 6.7 & 6.8 & 43 \\
92793 & 6.5 & 155.4 & 4.0 & 4.5 & 4.3 & 5.1 & 2.5 & 2.5 & 20 \\
58865 & 7.0 & 26.1 & 6.0 & $\mathrm{NaN}$ & 6.2 & 0.9 & 0.0 & $\mathrm{NaN}$ & 130 \\
71155 & 7.5 & 78.5 & 7.0 & 4.5 & 6.7 & 3.0 & 0.36 & 0.36 & 41 \\
61785 & 8.0 & 545.9 & 13.0 & 13.0 & 11.1 & 13.8 & 18.7 & 18.3 & 20 \\
71154 & 8.0 & 87.2 & 7.0 & 4.5 & 6.7 & 3.2 & 0.38 & 0.37 & 41 \\
71153 & 8.0 & 64.1 & 7.0 & 4.0 & 6.7 & 2.6 & 0.34 & 0.35 & 41 \\
30225 & 10.5 & 561.1 & 16.6 & 16.0 & 14.5 & 14.9 & 23.8 & 22.2 & 50 \\
90163 & 19.0 & 69.4 & 6.5 & 4.5 & 6.4 & 1.9 & 1.0 & 1.1 & 50 \\
\hline
\end{tabular}

NaN (Not a Number) means that no estimates were provided.

Digital Quaternary map (DQM) deposits identification: 20 Glaciofluvial sediments.

41 Ocean and coastal sediments, coherent, often great thickness.

43 Ocean, sea and beach sediments, patchy or thin cover over bedrock.

50 Fluvial (River and stream sediments).

70 Weathered deposits, not divided by thickness.

130 Exposed bedrock. 
Table 5. Jackknife cross-validation of sedimentary wells (the id. is the well number identification in the GRANADA database (NGU, 2017a). The measured length of well $D_{\text {well }}$, was compared to estimated sediment depth $D_{\text {obs }}$. In general, the real sediment depth is equal to or larger than the length of the sedimentary well: $D \geq D_{\text {well }}$, but for this cross-validation we let $D \simeq D_{\text {well }}$ because all wells were located in Fluvial sediments and they were drilled for water supply. See Tab.2 for explanation of table heading and abbreviations.

\begin{tabular}{ccccccccc}
\hline id. & $D_{\text {well }}$ & $L_{\text {obs }}$ & $D_{O K}^{*}$ & $D_{C K}^{*}$ & $D_{O K}^{\prime}$ & $D_{B K}^{\prime}$ & $D_{P}$ & $D_{P K}$ \\
\hline 49058 & 19.0 & 87.7 & 4.5 & 3.5 & 5.1 & 2.6 & 0.5 & 0.5 \\
49057 & 19.5 & 60.0 & 4.5 & 2.5 & 5.1 & 2.1 & 0.4 & 0.4 \\
4931 & 21.0 & 54.6 & 4.5 & 2.0 & 5.1 & 2.0 & 0.4 & 0.4 \\
4930 & 21.0 & 83.4 & 4.5 & 3.0 & 5.1 & 2.5 & 0.5 & 0.5 \\
4932 & 24.0 & 54.6 & 4.5 & 2.0 & 5.1 & 2.0 & 0.4 & 0.4 \\
4933 & 25.0 & 60.0 & 4.5 & 2.5 & 5.1 & 2.1 & 0.4 & 0.4 \\
33887 & 30.0 & 79.8 & 4.0 & 3.0 & 4.9 & 2.5 & 0.8 & 0.8 \\
4928 & 34.0 & 82.9 & 4.0 & 3.0 & 4.9 & 2.6 & 0.8 & 0.8 \\
4929 & 34.0 & 86.3 & 4.0 & 3.0 & 4.9 & 2.7 & 0.9 & 0.9 \\
54057 & 81.0 & 935.9 & 16.0 & 18.0 & 12.7 & 22.5 & 28.1 & 28.4 \\
\hline
\end{tabular}

Digital Quaternary map (DQM) deposits identification for all wells: 50 Fluvial (River and stream sediments).

Table 6. Mean absolute error $M_{A E}$, accuracy $A_{C}$, and precision $P_{C}$ of jackknife cross-validation of boreholes recorded after 2010 for ordinary kriging $O K$, cokriging $C K$, bedrock kriging $B K$, inverse modelling of the Poisson equation $P$, and kriging on residuals from the optimal Poisson equation $P K$. For inverse modelling results from the Poisson equation accuracy and precision was not calculated because the uncertainties was not calculated. The superscripts * and ' indicate either normal score transform or lognormal transform of the observations. Note that for sedimentary wells, the mean absolute error was calculated with the assumption that the length of the sedimentary wells was identical to the sediment depth. Accuracy and precision were not calculated for sedimentary wells because of this assumption.

\begin{tabular}{lcccccc}
\hline & $O K^{*}$ & $C K^{*}$ & $O K^{\prime}$ & $B K^{\prime}$ & $P$ & $P K$ \\
\hline Boreholes & & & & & & \\
$M_{A E}$ & 3.77 & 4.95 & 3.73 & 5.16 & 6.63 & 6.48 \\
$A_{C}$ & 0.53 & 0.45 & 0.60 & 0.20 & - & 0.21 \\
$P_{C}$ & 0.86 & 0.63 & 0.91 & 1.00 & - & 0.75 \\
\hline $\begin{array}{l}\text { Sedimentary wells } \\
M_{A E}\end{array}$ & 25.35 & 26.60 & 25.04 & 26.50 & 27.51 & 27.48 \\
\hline $\begin{array}{l}M_{A E}: \text { Mean absolute error, Eq.23. } \\
A_{C}: \text { Accuracy, Eq.24. }\end{array}$ & & & & & \\
$P_{C}:$ Precision, Eq.25. & & & & & &
\end{tabular}

